\title{
Surface circulation in the eastern North Atlantic, from drifters and altimetry
}

\author{
C. Sena Martins ${ }^{1}$ \\ Instituto de Oceanografia, Universidade de Lisboa, Lisbon, Portugal
}

M. Hamann

Institut für Meereskunde, Universität Kiel, Kiel, Germany

\section{A. F. G. Fiúza}

Instituto de Oceanografia, Universidade de Lisboa, Lisbon, Portugal

Received 30 March 2000; revised 6 August 2001; accepted 23 August 2001; published 18 December 2002.

[1] A description of the near-surface circulation and its properties is the result of the analysis of a drifting buoy data set in the eastern North Atlantic between the Iberian Peninsula, the Azores, and the Canary Islands. World Ocean Circulation ExperimentTropical Ocean-Global Atmosphere experiment drifters equipped with holey sock drogues centered at $15 \mathrm{~m}$ depth collected a total of 14.4 years of data. The drifters sampled a rather inhomogeneous velocity field with a weak mean flow regime and eddies of different scales. They meandered southward everywhere in the study region, except in the Iberian coastal transition zone north of $41^{\circ} \mathrm{N}$ where they headed northward. The near-surface mean velocity field obtained from the drifter data set shows all important mean currents, including the poleward Portugal Coastal Countercurrent during the fall, winter, and early spring off western and northern Iberia, the southward Portugal Coastal Current, the slow offshore southward flow of the Portugal Current during the whole year, the southwestward Canary Current, and the eastward Azores Current, which extends to the vicinity of the African coast near the Gulf of Cadiz. Maps of the eddy kinetic energy field were obtained from the drifters and from satellite altimetry. It provides the largest part of the total kinetic energy. The rate of dispersion is estimated from the Lagrangian statistics of the drifting buoys. The dispersion of the drifters in the study region is well modeled by a simple description of eddy diffusion assuming homogeneous turbulence. Ensemble mean diffusivities $K$ and the Langrangian integral length scales and timescales $(L$ and $T)$ were obtained for the zonal and meridional directions. The sea surface temperature measured along the drifter trajectories is used to produce estimates of the eddy diffusivity, which is compared with the diffusivity estimates obtained from the theory of Taylor. The eddy diffusivity is found to be approximately proportional to the eddy kinetic energy. Discrete eddies and meanders were observed using drifters and altimetry in order to map and describe their geographical distribution and characteristics in the eastern North Atlantic. INDEX TERMS: 4219 Oceanography: General: Continental shelf processes; 4512 Oceanography: Physical: Currents; 4516 Oceanography: Physical: Eastern boundary currents; 4520 Oceanography: Physical: Eddies and mesoscale processes; 4568 Oceanography: Physical: Turbulence, diffusion, and mixing processes; KEYWORDS: drogued WOCE TOGA drifters, Azores Current, Canary Current, Portugal Current, Portugal Countercurrent

Citation: Martins, C. S., M. Hamann, and A. F. G. Fiúza, Surface circulation in the eastern North Atlantic, from drifters and altimetry, J. Geophys. Res.,, 107(C12), 3217, doi:10.1029/2000JC000345, 2002.

\section{Introduction}

[2] The major part of the recirculation in the North Atlantic subtropical gyre occurs in the western Atlantic, but considerable recirculation occurs also in the eastern

\footnotetext{
${ }^{1}$ Now at Institut für Meereskunde, Universität Kiel, Kiel, Germany.
}

Atlantic. Several studies in this area are based on hydrographic stations and describe the geostrophic flow field [e.g., Stramma, 1984; Sy, 1988; Klein and Siedler, 1989]. There is, though, still a lack of detailed information about the surface circulation in the northeast region of the Atlantic Ocean.

[3] Several oceanographic programs were set in recent years, aiming at a more detailed study of the ocean circulation. One of the components of those programs 
involved the elaboration of ocean models that enable not only the description of the velocity field but also its forecast.

[4] A method to get more insight into the circulation consists of using satellite-tracked drifting buoys to obtain current velocities since their trajectories provide a rich description of the oceanic circulation over a broad range of scales including large-scale flows and mesoscale eddy fields. A combination with altimetry data complements the description.

[5] As part of the Portuguese contribution to the World Ocean Circulation Experiment (WOCE)-Surface Velocity Programme, the present study aimed at the surface circulation in the region of the world ocean puzzle located between the Iberian Peninsula, the Azores Archipelago, and the Canary Islands using the trajectories of drifters tracked by satellites during about 2 years. It was carried out under the Multidisciplinary Oceanographic Research in the Eastern Boundary of the North Atlantic (MORENA) and the Development of Satellite Oceanography in Portugal (POSATOCEAN) projects. One of the objectives of these projects was the study of the different ramifications of the Portugal Current System.

[6] The paper is organized as follows: In section 2 the data set and the processing procedures are presented. In section 3 the methodology is described, together with the primary and the Lagrangian statistics. In section 4 the summary of the main results obtained is presented.

\section{Data Set and Method}

\subsection{Drifter Data}

\subsubsection{Overview}

[7] The data set spans the period of about 2 years, from January 1993 to October 1994, and consists in data from 31 drifters deployed in the Portugal Current System. Sixteen drifters were deployed near the western coast of Portugal: 3 in May 1993, 11 in November 1993, and 2 at the end of September of 1994. The other 15 drifters were deployed along the commercial ship route between Lisbon and the Azores Islands between January and November of 1993.

[8] The drifters were equipped with a holey sock-type drogue centered at $15 \mathrm{~m}$ depth and were designed to minimize surface drag by both wind and waves. According to Niiler and Paduan [1995] the slip of the WOCE-Tropical Ocea-Global Atmosphere experiment (TOGA) drifter's drogue relative to the water is $<2 \mathrm{~cm} \mathrm{~s}^{-1}$ for winds up to $20 \mathrm{~m} \mathrm{~s}^{-1}$. The instruments were programmed to transmit continuously, and they were tracked until they ceased to transmit. A thermistor mounted on the surface float of the drifter (at about $30 \mathrm{~cm}$ depth) yields the temperature records.

\subsubsection{Data Processing}

[9] The drifter data were received directly at the Space Oceanography Center of the Institute of Oceanography of the University of Lisbon, via the high-resolution picture transmission (HRPT) data stream through NOAA 9, 10, 11, and 12 satellites. An average of four positions was obtained per day for each one of the drifters. The position of one of the emitters was known, which allowed an estimate of the inaccuracy introduced by the satellite positioning. The positions are accurate to within $1 \mathrm{~km}$, which implies an error of about $1 \mathrm{~cm} \mathrm{~s}^{-1}$ for daily averaged speeds.

[10] Occasional gaps in the time series of longitude and latitude, involving intervals between 12 and 36 hours, were filled by linearly interpolating each one of these time series to four positions per day before applying the cubic spline interpolation to six positions per day. In order to account for high-frequency tidal and inertial band wave energy and to avoid aliasing the energy into low-frequency motions that are the primary interest of the study, these drifter positions were averaged over a 24 hour interval, thus obtaining a uniformly sampled time series of daily positions. The velocities were calculated using these position time series and a centered difference scheme.

[11] The temperature data set was also averaged daily. Occasional gaps in the temperature time series were filled before by linear interpolation. The time series used in the next sections are the 24 hour average of the 4 hourly interpolated data.

\subsubsection{Data Temporal and Spatial Distribution}

[12] A total of 5248 buoy data days were obtained. The observations cover about 665 days; the meridional and zonal range are $\sim 2000 \mathrm{~km}$. The number of observations per month increases from January to December of 1993, when the maximum of 659 observations was reached, and decreased afterward. The data were collected in the region bounded by $27^{\circ}-4^{\circ} \mathrm{W}$ and $25^{\circ}-45^{\circ} \mathrm{N}$. The Iberian "coastal" MORENA region is defined by $12^{\circ}-4^{\circ} \mathrm{W}$ and $36^{\circ}-46^{\circ} \mathrm{N}$. The remaining area contains the PO-SATOCEAN data. The portion of the data set with useful temperature measurements corresponds to $95 \%$ of the buoy data days. The seasonal distribution of this subset is similar to that of the full data set.

[13] The majority of the measurements in the MORENA area took place in the winter and fall. The analysis performed here is then representative of that time of the year.

\subsection{Altimetry Data}

[14] The altimetry data set used was the 7 years (19921999) of TOPEX/Poseidon and ERS-1/2 sea level anomaly (SLA) provided by Archiving Validation and Interpretation of Satellite Data in Oceanography (AVISO). After elimination of anomalous SLA data the along-track data were filtered using a Butterworth filter with a cutoff wavelength of $70 \mathrm{~km}$ in order to smooth the data to eliminate noise. Residual sea surface velocities were calculated using the geostrophic relation

$$
V_{\mathrm{geo}}=\frac{\mathrm{g}}{f} \frac{d h}{d s}
$$

where $f$ represents the Coriolis parameter, $g$ is the acceleration due to gravity, $s$ is the along-track distance, and $h$ is the residual sea surface height. The eddy kinetic energy (EKE) was calculated using

$$
\mathrm{EKE}=\left(\frac{\mathrm{g}}{f}\right)^{2}\left\langle\left(\frac{d h}{d s}\right)^{2}\right\rangle,
$$

where angle brackets designate a time average. The variance of eddy velocity is seasonally averaged at each position and gridded afterward using objective analysis.

\section{Circulation and Statistics}

\subsection{Drifter Tracks}

[15] Figure 1 shows all drifter trajectories that form the data set. At first glance a chaotic image is associated with 


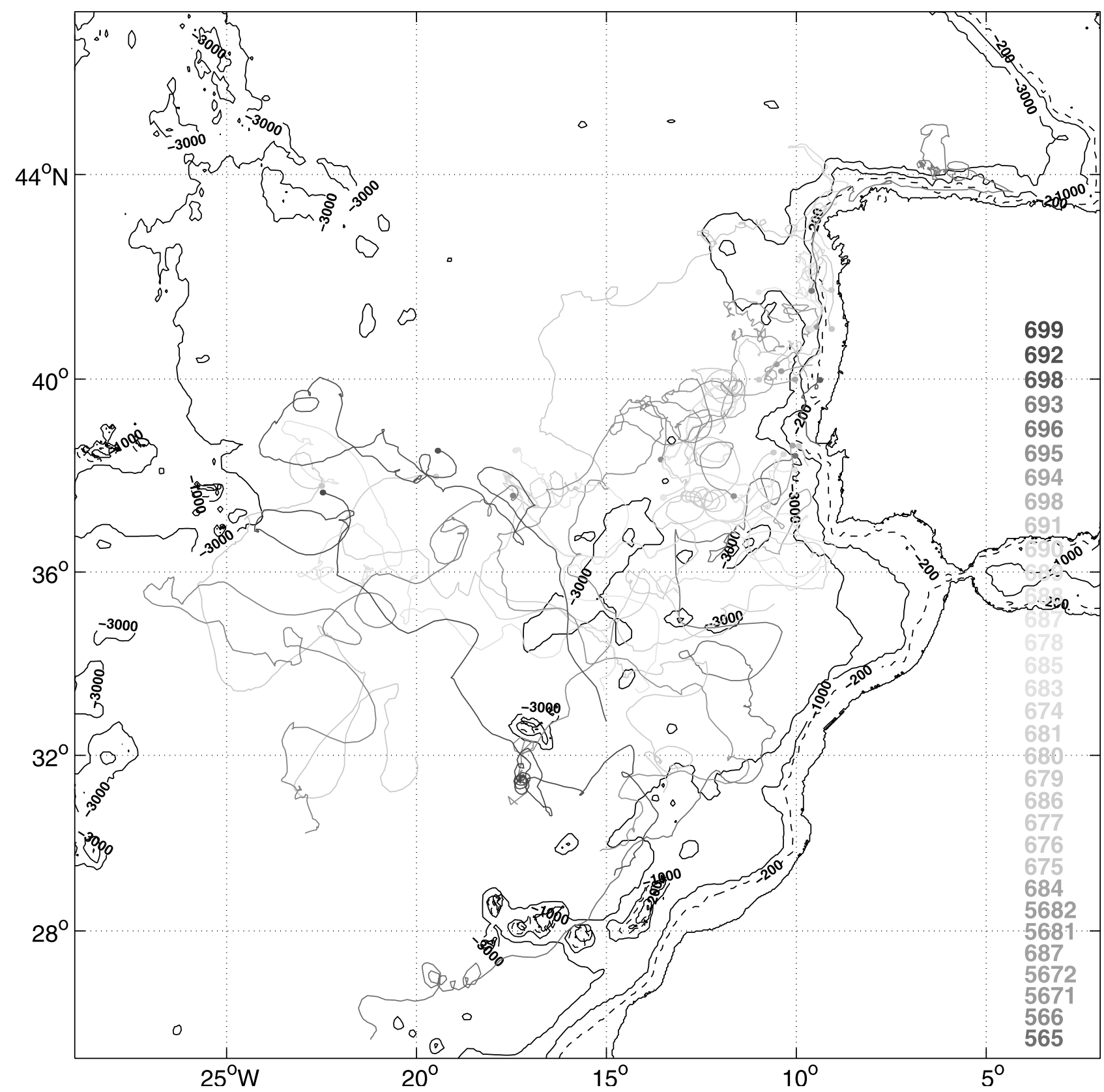

Figure 1. WOCE-TOGA surface $(15 \mathrm{~m})$ drifter trajectories between January 1993 and October 1994. The drifter identification numbers are indicated on the right; the color corresponds to the color of the trajectory. The starting point is indicated by a dot in the same color. See color version of this figure at back of this issue.

these trajectories reflecting the mesoscale variability. However, a more detailed look reveals the patterns of the largescale circulation. There is evidence of a slow southward flow regime everywhere in the study region, except in the Iberian coastal transition zone (MORENA), where the drifters were transported by a poleward current during fall, winter, and early spring. Near the Portuguese coast the drifters were generally transported southward south of about $41^{\circ} \mathrm{N}$, and zonal between $40^{\circ}-43^{\circ} \mathrm{N}, 10^{\circ}-12^{\circ} \mathrm{W}$.

[16] Some of the drifters were caught by the eastern branches of the subtropical anticyclonic gyre. One of the drifters deployed offshore of Portugal was transported southward in early June 1994, eastward by the Azores
Current, then describing an anticyclonic loop, and entered the southwestward Canary Current, again describing several anticyclonic loops south of the Canary Islands.

\subsection{Primary Statistics}

[17] The overall mean velocity is $U=(0.0 \pm 0.8,-2.1 \pm$ $0.8) \mathrm{cm} \mathrm{s}^{-1}$, where the average velocity components are presented together with the error $E$ of the mean value $(95 \%$ confidence interval according to Student's $t$ test) [see also Krauss and Böning, 1987]:

$$
\boldsymbol{t}_{n-1 ; \alpha / 2} \frac{\sqrt{\sigma^{2}}}{\sqrt{N^{*}}}
$$


where $t_{n-1}$ represents the Student's $t$ parameter, $\sigma^{2}$ is the sample variance, $\alpha / 2=0.025$, and $N^{*}$ is the number of independent observations: $N^{*}=N \Delta t / 2 T$, where $N$ is the number of drifter days, $\Delta t$ represents the sample rate, and $T$ is the Lagrangian integral timescale (to be defined later). Since $T$ ranges between 2 days and about a week, the decorrelation scale is chosen to be 10 days. This choice decreases the number of degrees of freedom, and thus the errors calculated below are maximum errors. However, we are sure that the observations are decorrelated.

[18] Since the drifters sampled a very inhomogeneous velocity field with weak mean flow and eddies of different scales, the assumption that the flow structure in the whole study area may be meaningfully characterized by a single velocity could be questioned. However, it reveals an overview of the statistics. Assuming homogeneity in smaller areas, mean values and standard deviations have been obtained by averaging over time and ensembles that correspond to the MORENA and PO-SATOCEAN regions. The dependency of the mean values on the number of drifter days for the ensembles PO-SATOCEAN and MORENA reveals that in general, about 150 buoy days are required to stabilize the statistics and about double (a year) are required to obtain statistically reliable values [Martins, 1997]. After the first 5 months the cumulative mean values and standard deviations generally settle down to $<1 \mathrm{~cm} \mathrm{~s}^{-1}$. The results of prime statistics are summarized in Table 1. Uncertainties in the averages are the consequence of the limited number of buoys per ensemble and of records that are not long enough.

[19] The meridional flow computed from the whole data set in the region is to the south in winter and spring. The velocity statistics show a significant southward flow in the PO-SATOCEAN region. The correspondent zonal flow is only significant in fall, when it flows eastward. In the MORENA region the significant average of the zonal flow in winter is westward, while in spring it changes to eastward. The variances of the zonal and meridional components of velocity are generally higher in the POSATOCEAN region than in the MORENA region, having a maximum in the PO-SATOCEAN region and a minimum in the MORENA region in the winter season. This minimum in the variance might be associated with the winter Portugal Coastal Countercurrent whose average is twice the value of the correspondent error.

\subsection{Velocity Field}

[20] In order to study the large-scale variability of the field it is assumed that the statistics are stationary. Drifter velocities were averaged in spatial bins of $2^{\circ}$ latitude per $3^{\circ}$ longitude, except where the number of data was too small. In those cases the bins were enlarged. Bins with higher mean velocity values tend to have a smaller amount of data since drifters do not spend much time there.

[21] A relatively high number of drifters were deployed near the coast to study the fall/winter poleward Portugal Coastal Countercurrent, but most of them left the region of deployment and did not return. Since the flow in that region is variable in time, the result is biased because only few drifter data were obtained in this region in summer. The problem is similar near the edges of the drifter array because the observations are from drifters that arrived from the denser region of the array.
Table 1. Statistical Results of the Velocity Field ${ }^{\mathrm{a}}$

\begin{tabular}{cccccc}
\hline \multicolumn{1}{c}{$\begin{array}{c}\bar{u} \pm E, \\
\mathrm{~cm} \mathrm{~s}^{-1}\end{array}$} & $\begin{array}{c}\bar{v} \pm E, \\
\mathrm{~cm} \mathrm{~s}^{-1}\end{array}$ & $\begin{array}{c}\overline{u^{\prime 2}}, \\
\mathrm{~cm}^{2} \mathrm{~s}^{-2}\end{array}$ & $\begin{array}{c}\overline{\nu^{\prime 2}}, \\
\mathrm{~cm}^{2} \mathrm{~s}^{-2}\end{array}$ & $N$ \\
\hline PO-SATOCEAN & $-0.7 \pm 1.4$ & $-2.0 \pm 1.1^{\mathrm{b}}$ & 98.9 & 85.8 & 3556 \\
Fall & $2.2 \pm 1.4^{\mathrm{b}}$ & $-2.9 \pm 1.3^{\mathrm{b}}$ & 83.9 & 77.4 & 820 \\
Winter & $0.6 \pm 2.5$ & $-2.0 \pm 2.3$ & 115.2 & 109.1 & 972 \\
Spring & $-1.3 \pm 2.1$ & $-2.3 \pm 1.6^{\mathrm{b}}$ & 98.2 & 74.7 & 896 \\
Summer & $-0.6 \pm 2.3$ & $-5.0 \pm 2.6^{\mathrm{b}}$ & 92.8 & 79.2 & 868 \\
MORENA & $0.6 \pm 1.3$ & $-1.1 \pm 1.8$ & 71.3 & 66.4 & 1692 \\
Fall & $0.6 \pm 1.8$ & $0.3 \pm 2.0$ & 66.4 & 76.8 & 645 \\
Winter & $-1.4 \pm 0.7^{\mathrm{b}}$ & $-1.8 \pm 0.9^{\mathrm{b}}$ & 76.5 & 53.4 & 592 \\
Spring & $0.9 \pm 0.5$ & $-3.1 \pm 2.3^{\mathrm{b}}$ & 72.5 & 58.2 & 300 \\
Summer & $0.7 \pm 4.9$ & $-0.9 \pm 2.5$ & 62.6 & 84.4 & 155 \\
\hline
\end{tabular}

${ }^{\mathrm{a}}$ The zonal $(\bar{u})$ and meridional $(\bar{v})$ regional and seasonal averages, errors $(E)$, and variances $\left(\overline{u^{\prime 2}}, \overline{v^{\prime 2}}\right)$ are indicated, as well as the number of drifter days $(N)$.

${ }^{\mathrm{b}}$ The results that are statistically significant.

[22] According to Davis [1985], Eulerian velocity statistics based on drifter observations can be biased in mainly three ways: (1) by temporally and spatially nonuniform drifter sampling, (2) by drift of the buoy drogue in horizontally nondivergent flows (the effect of convergences cannot be estimated), and (3) by the inhomogeneity of the small-scale eddy dispersive velocity field, which causes a diffusive drift in Lagrangian trajectories. According to the author an estimate of the sampling array bias is given by: $-K_{i i} \operatorname{Grad}[\ln (C)]$, where $K_{i i}$ represents the horizontal diffusivities and $C$ represents the drifter concentration. A bias of $(-0.2,-0.3) \mathrm{cm} \mathrm{s}^{-1}$ was obtained for the zonal and meridional directions in the SATOCEAN region, while the corresponding values for the MORENA region were $(0.04,-0.02) \mathrm{cm} \mathrm{s}^{-1}$, respectively. A southward eddy transport is then expected in both regions. These results are small when compared to the averages in Table 1.

\subsubsection{General Circulation}

[23] Figure 2 shows the mean velocity field obtained from the drifter data, revealing for the first time the details of the current system associated with the eastern branch of the subtropical gyre: The broad and weak Portugal Current (PC) flows to the south between continental Portugal and the Azores Islands; the poleward Portugal Coastal Countercurrent flows along the west and north coasts of the Iberian Peninsula; the Azores Current flows to the east between $34^{\circ}$ and $36^{\circ} \mathrm{N}$ to the vicinity of the African coast, and the Canary Current flows along the African coast to the southwest. The maximum speeds are found in the Azores and Canary Currents.

[24] The ellipses indicate the principal directions of variance, and the corresponding axes indicate the errors of the mean values. The principal axes undergo significant variations over the study area, showing significant isotropy at $95 \%$ confidence level based on an $F$ test and on a Lagrangian timescale of 10 days. Near the main currents the major axis is aligned with the direction of the flow, as, for example, near the poleward current along the Iberian coast, the Azores, and the Canary Currents.

[25] The average and correspondent error for the zonal and meridional velocity components in the Canary Current calculated from 134 drifter days south of about $31^{\circ} \mathrm{N}$ are given by $-8.1 \pm 6.4$ and $-6.0 \pm 6.4 \mathrm{~cm} \mathrm{~s}^{-1}$, respectively, with maximum values in the north-south and east-west directions of $\sim 35 \mathrm{~cm} \mathrm{~s}^{-1}$ (Table 2). In the PC the values 


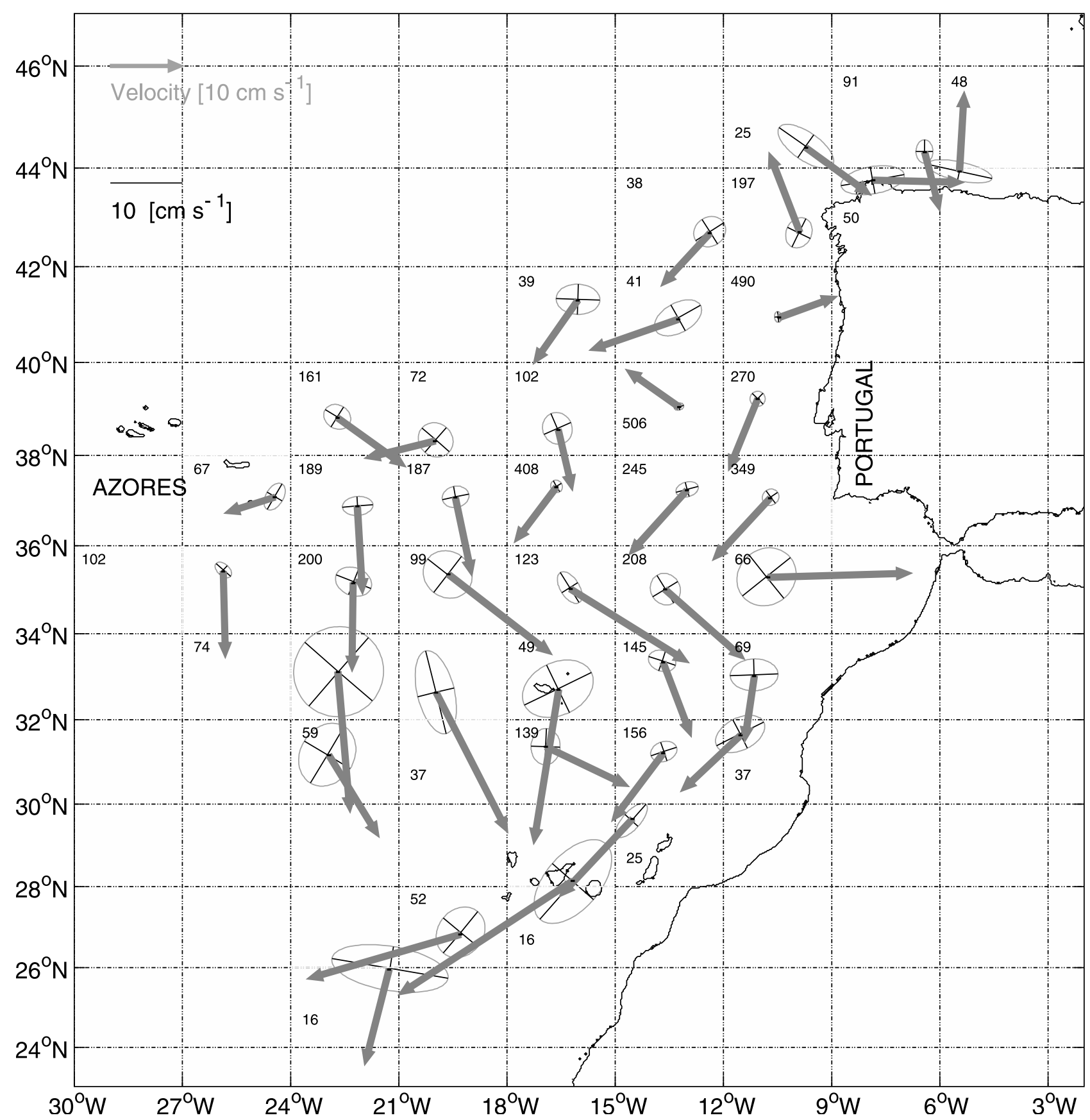

Figure 2. Average velocity field in the northeast Atlantic as derived from near-surface drifters. The arrow's origin is located at the average drifter positions in each box, and its length is directly proportional to the velocity magnitude. The ellipses indicate the principal directions of variance, and the correspondent axes indicate the errors. The arrow corresponding to a $10 \mathrm{~cm} \mathrm{~s}^{-1}$ mean velocity and a linear segment of $10 \mathrm{~cm} \mathrm{~s}^{-1}$ for the error are indicated on top of the figure. The number of drifter days used in the averages is indicated on the upper left corner of each box whose geometry is variable in order to improve statistical reliability.

are $1.6 \pm 1.3 \mathrm{~cm} \mathrm{~s}^{-1}$ to the west and $1.6 \pm 1.2 \mathrm{~cm} \mathrm{~s}^{-1}$ to the south, respectively, with a maximum speed of $5.7 \mathrm{~cm} \mathrm{~s}^{-1}$ in the meridional direction, revealing the slow movement that characterizes this current. For these calculations, 1989 drifter days were used, in the box $36^{\circ}-44^{\circ} \mathrm{N}, 24^{\circ}-12^{\circ} \mathrm{W}$.

\subsubsection{Azores Current}

[26] The trajectories of the drifters (Figure 1) show the eastward Azores Current between $34^{\circ}-36^{\circ} \mathrm{N}$, with eddies and meanders having scales of $O(100 \mathrm{~km})$. There are also trajectory segments in which the drifters moved westward, revealing the presence of a possible countercurrent located on the northern edge of the Azores Current. Figure 3 shows the velocity field and the principal axes (errors of the mean values) in the region $34^{\circ}-36^{\circ} \mathrm{N}, 27^{\circ}-12^{\circ} \mathrm{W}$ obtained by averaging over a grid of variable geometry according to the amount of available data. The Azores Current can be seen as 
Table 2. Statistics of the Main Currents ${ }^{\mathrm{a}}$

\begin{tabular}{|c|c|c|c|c|}
\hline $\begin{array}{c}\text { Main Currents in } \\
\text { Geographical Regions }\end{array}$ & $\begin{array}{l}\bar{u} \pm E \\
\mathrm{~cm} \mathrm{~s}^{-1}\end{array}$ & $\begin{array}{c}\bar{v} \pm E \\
\mathrm{~cm} \mathrm{~s}^{-1}\end{array}$ & $\begin{array}{c}\text { Maximum } \\
\text { Speed, } \mathrm{cm} \mathrm{s}^{-1}\end{array}$ & $N$ \\
\hline PC: $36^{\circ}-44^{\circ} \mathrm{N}, 24^{\circ}-12^{\circ} \mathrm{W}$ & $1.6 \pm 1.3^{\mathrm{b}}$ & $-1.6 \pm 1.2^{\mathrm{b}}$ & 6 & 1989 \\
\hline $\mathrm{AzC}: 34^{\circ}-36^{\circ} \mathrm{N}, 27^{\circ}-12^{\circ} \mathrm{W}$ & $4.9 \pm 2.8^{\mathrm{b}}$ & $-3.7 \pm 2.6^{\mathrm{b}}$ & 40 & 747 \\
\hline $\mathrm{CC}$ : south of $31^{\circ} \mathrm{N}$ & $-8.1 \pm 6.4^{\mathrm{b}}$ & $-6.0 \pm 6.4^{\mathrm{b}}$ & 50 & 134 \\
\hline SPCC: $37^{\circ}-41^{\circ} \mathrm{N}$ (east of $10^{\circ} \mathrm{W}$ ) & $2.7 \pm 2.9$ & $-4.2 \pm 3.4^{\mathrm{b}}$ & 30 & 133 \\
\hline PCC: $41^{\circ}-43.3^{\circ} \mathrm{N}$ (east of $\left.10^{\circ} \mathrm{W}\right)$ & $-0.6 \pm 1.8$ & $6.1 \pm 3.6^{\mathrm{b}}$ & 43 & 232 \\
\hline PCC: north of $43.3^{\circ} \mathrm{N}$ & $1.0 \pm 1.6$ & $0.5 \pm 0.3^{\mathrm{b}}$ & & 229 \\
\hline
\end{tabular}

${ }^{a}$ Abbreviations are as follows: Portugal Current, PC; Azores Current, AzC; Canary Current, CC; Southward Portugal Coastal Current, SPCC; Portugal Coastal Countercurrent, PCC; and number of drifter days, $N$.

${ }^{\mathrm{b}}$ The results that are statistically significant.

an eastward current extending into the Gulf of Cadiz. The average zonal and meridional speeds as obtained from 747 drifter days are $4.9 \pm 2.8$ and $-3.7 \pm 2.6 \mathrm{~cm} \mathrm{~s}^{-1}$, respectively. Maximum zonal speeds are relatively high: $40 \mathrm{~cm}$ $\mathrm{s}^{-1}$ to the east and $25 \mathrm{~cm} \mathrm{~s}^{-1}$ to the west. Secondary maximum speeds of $20 \mathrm{~cm} \mathrm{~s}^{-1}$ to the southeast are observed along the latitude band $34^{\circ}-35^{\circ} \mathrm{N}$. A higher number of observations would be required to address the circulation involving the Azores Current in the vicinity of the Gulf of Cadiz in order to understand the local circulation in that region. The analysis of seasonal variability aiming at the identification of a shift in the position of the Azores Current, or a variation in its width [Klein and Siedler, 1989], was inconclusive, mainly because of the insufficient amount of data and the irregular spatial and temporal data distribution.

\subsubsection{Portugal Coastal Countercurrent}

[27] The surface circulation off the western coast of the Iberian Peninsula is strongly influenced by the atmospheric pressure distribution in the North Atlantic. In summer, when the Azores high-pressure cell is located in the central Atlantic and the Greenland low-pressure cell is less intense, the resulting pressure gradient force leads to southward winds along the Iberian coast, which in turn induces upwelling as a result of the associated offshore Ekman transport, and the surface flow is southward, in response to the "Portuguese Trades" [Wooster et al., 1976; Fiúza et $a l ., 1982]$. During the winter season the pressure system Azores high-Greenland low migrates southward, and a poleward alongshore flow occurs [Wooster et al., 1976; Frouin et al., 1990]. Hydrographic data together with satellite infrared imagery were used in order to put in evidence and investigate the origin of this poleward current [Frouin et al., 1990; Haynes and Barton, 1990]. According to Frouin et al. [1990] it is the combination of the onshore Ekman transport induced by the southerly winds along the Portuguese coast, together with the geostrophic adjustment of the large-scale oceanic zonal flow as it impinges upon the upper continental margin of the western Iberian Peninsula, that mainly explain the existence of the poleward flow.

[28] One of the purposes of the present drifting buoy program was the study of the Portugal Coastal Countercurrent (PCC). The 539 buoy data days from 11 drifters were obtained in the MORENA region from fall of 1993 to spring of 1994. These observations showed the presence of the PCC from fall to early spring months. The PCC was tracked by five drifters deployed in November 1993 near the Iberian coast north of $41^{\circ} \mathrm{N}$ (Figure 4). Another drifter deployed in fall north of this latitude and farther offshore was first transported eastward and then northward, while south of $41^{\circ} \mathrm{N}$, which seems to mark a bifurcation of the circulation, the flow was to the south and west during the period of observation. After reaching the northwest corner of Spain the current turns eastward at almost a right angle following the coastline, apparently to conserve potential vorticity [Frouin et al., 1990]. Drifter 696 deployed near the coast at the highest latitude was transported poleward over a distance of about $670 \mathrm{~km}$ between November 1993 and 18 January 1994, surrounding the Cape Finisterre and entering the Bay of Biscay.

[29] The mean speed in the PCC obtained with the drifters (Figure 4) is $13.5 \pm 5.7 \mathrm{~cm} \mathrm{~s}^{-1}$. On the west coast of Iberia the mean speed is $15.1 \pm 4.4 \mathrm{~cm} \mathrm{~s}^{-1}$, and on the northern coast, where a maximum speed of $42.8 \mathrm{~cm} \mathrm{~s}^{-1}$ was reached, it is $17.4 \pm 9.9 \mathrm{~cm} \mathrm{~s}^{-1}$. The EKE is $42.0 \pm 23.2 \mathrm{~cm}^{2} \mathrm{~s}^{-2}$, the mean kinetic energy (MKE) is $84 \mathrm{~cm}^{2} \mathrm{~s}^{-2}$, and the mean temperature is $15.0 \pm 0.6^{\circ} \mathrm{C}$. The EKE increases from about $30 \mathrm{~cm}^{2} \mathrm{~s}^{-2}$ west of Iberia to about $60 \mathrm{~cm}^{2} \mathrm{~s}^{-2}$ north of Iberia. The mean speed is inferior to the values of Frouin et al. [1990], who estimated values of $20-30 \mathrm{~cm} \mathrm{~s}^{-1}$. The drifter trajectories indicate a width of the current from 45 to $53 \mathrm{~km}$

[30] The PCC is usually trapped to the continental slope, but in the region $42^{\circ}-43^{\circ} \mathrm{N}$ some drifters showed meandering of the flow away from the shelf break. One of the drifters initially in the PCC even separated from this current along the western coast off Iberia (Figure 1) involved in anticyclonic as well as cyclonic eddies and meanders. Particularly, a bifurcation zone was identified near $43^{\circ} \mathrm{N}$ west of Cape Finisterre. Drifter 674 diverged from the PCC near the cape, in March 1994, being transported to the north throughout this month with a mean speed of $9.3 \pm 5.4 \mathrm{~cm}$ $\mathrm{s}^{-1}$ and to the south again almost retracing its path in the beginning of April with a mean speed of $17.0 \pm 4.0 \mathrm{~cm} \mathrm{~s}^{-1}$. In the subsequent months the trajectory of this drifter revealed episodes of southward coastal flow in April and in the beginning of May. However, the PCC is still present during a week at the end of April [Martins, 1997].

[31] The circulation pattern off Iberia changed in January of 1994. The wind field based on National Centers for Environmental Prediction reanalysis (not presented here) shows the changes in the meteorological conditions with northward winds being replaced by southward winds around 16 January being the main reason for the disappearance of the poleward current within 1-2 days. The drifters no longer followed the PCC but were transported to the west and southwest. A satellite image from NOAA 11, obtained the same day (18 January 1994) the divergence of the drifters from the PCC occurred (Figure 5), allows the 

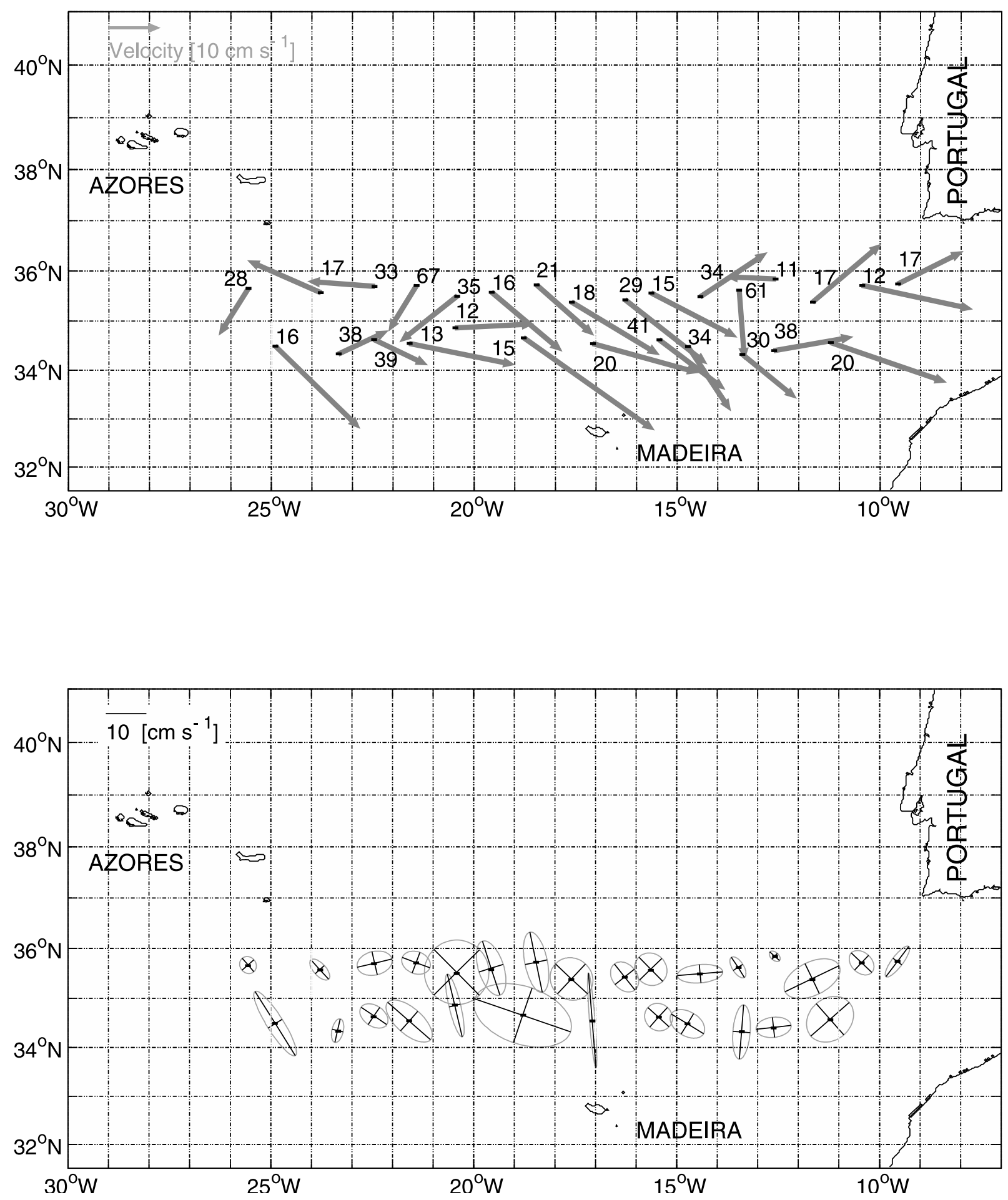

b

Figure 3. (a) Average velocity field (as in Figure 2) in the Azores Current. (b) The correspondent directions of variance (as in Figure 2) in boxes of variable geometry in order to improve statistical reliability.

identification of the PCC sea surface temperature pattern. This image reveals that the PCC extends into the Bay of Biscay to $4^{\circ} \mathrm{W}$. Satellite images have shown this flow as far east as the French border [Frouin et al., 1990]. A segment of the drifter 696 trajectory was superimposed on the image, showing good correspondence with the temperature features and revealing that this trajectory segment adjusts quite well to the PCC. After 18 January the drifter was transported northwestward into the Bay of Biscay. Throughout February and March its trajectory shows several cyclonic loops (Figure 1).

[32] Near $40.5^{\circ} \mathrm{N}$ and between $11^{\circ}$ and $9.5^{\circ} \mathrm{W}$ the flow averaged in geographical bins is mainly eastward (Figure 6a). After impinging on the coast it separates into the northward 


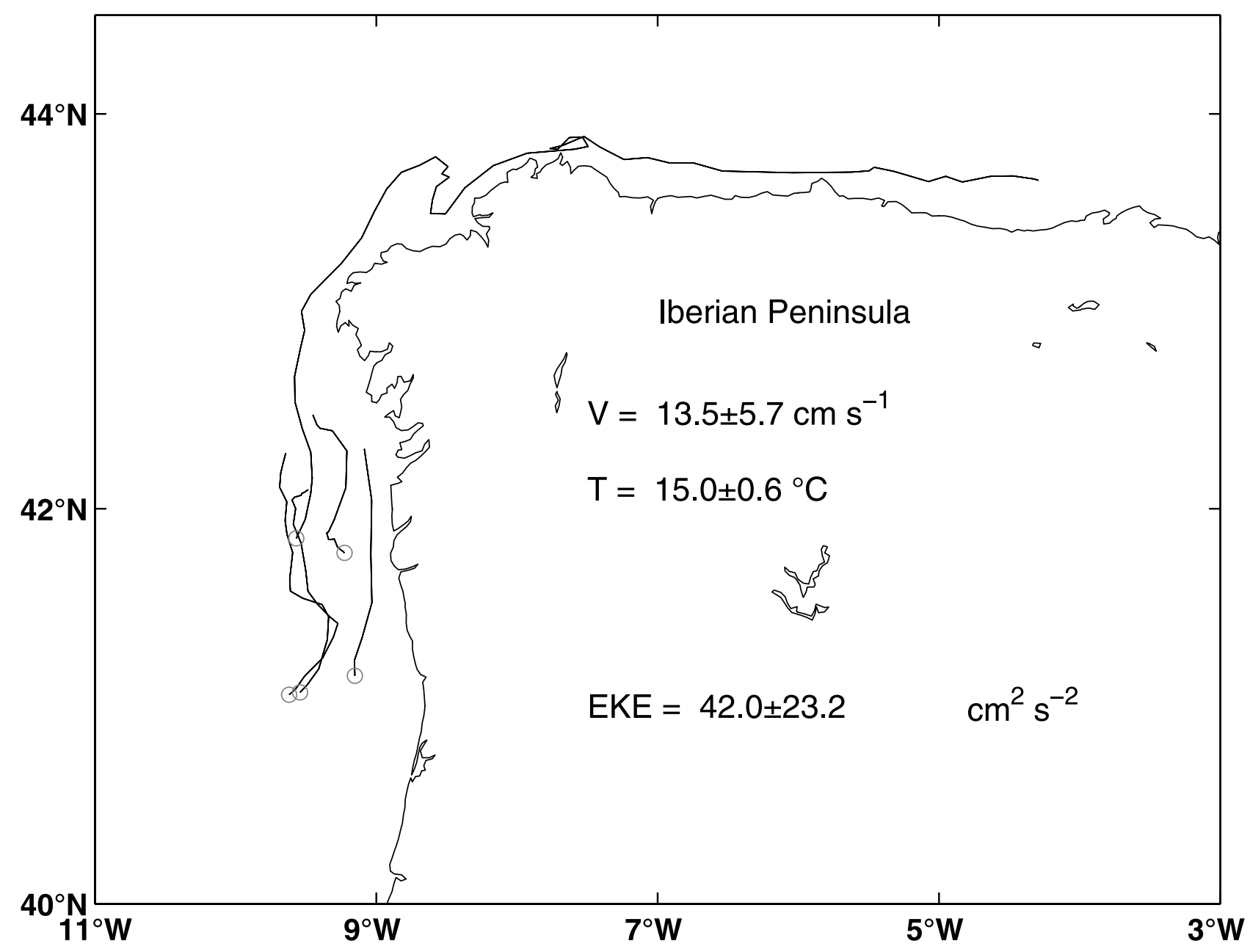

Figure 4. Drifter trajectories in the PCC. The circles indicate the initial positions.

PCC and a southward coastal current. The PCC is a narrow coastal current located east of $10^{\circ} \mathrm{W}$ and north of $41^{\circ} \mathrm{N}$ (Figure 6a). It shows a relatively strong northward velocity between $41^{\circ}$ and $43.3^{\circ} \mathrm{N}$ (Table 2). The southward coastal current between $37^{\circ}$ and $41^{\circ} \mathrm{N}$ (east of $10^{\circ} \mathrm{W}$ ), sometimes present even in winter, though it seems to prevail during the summer half year, is the southward PCC (SPCC). The major axes of variability (Figure 6b) are aligned with both coastal currents (PCC and SPCC), showing higher variability in the $\mathrm{PCC}$ in the northern part of the Iberian coast and in the SPCC near Cape of Roca at about $39^{\circ} \mathrm{N}$.

[33] Similar eastern poleward boundary countercurrents have been observed, such as the Leeuwin Current off the west coast of Australia or the Davidson Current off California. Both currents flow poleward near the coast in the winter, against the direction of the local wind. According to McCreary et al. [1986] the Leeuwin Current has its origin in the thermohaline forcing because of a meridional increase of surface density associated with the poleward cooling of the sea surface. The dynamic height of the sea surface decreases poleward, driving an eastward geostrophic current in the interior ocean, which in turn forces coastal downwelling at an eastern ocean boundary and generates a poleward surface coastal current and an equatorward undercurrent. Their model results showed that the maximum in the strength of the Leeuwin Current is due to a relaxation of the opposing wind stress, allowing a stronger thermohaline current.

[34] This could also be a driving mechanism for the Iberian poleward surface flow. Pollard and $P u$ [1985] showed that the interior geostrophic flow is directed eastward in a broad band of the North Atlantic, north of $33^{\circ} \mathrm{N}$.

[35] McCreary et al. [1987] concluded that the wintertime relaxation of the wind off California is not the primary cause of the Davidson Current since it originates as a shallower and weaker poleward surface current than the observed one. Positive wind curl is the mechanism that generates both the poleward Davidson Current and the equatorward flow offshore of $100 \mathrm{~km}$, and the authors stressed the dynamical importance of vertical and horizontal mixing, the near-surface pycnocline, and the remote winds of Baja California.

\subsection{Eddy Kinetic Energy}

[36] The outstanding information of the EKE distribution in the North Atlantic is, according to Krauss and Käse [1984] and Brügge [1995], that the EKE is concentrated along the main currents, which therefore determine its distribution. Several authors [Richardson, 1983; Colin de Verdière, 1983; Krauss and Böning, 1987; Brügge, 1995] 


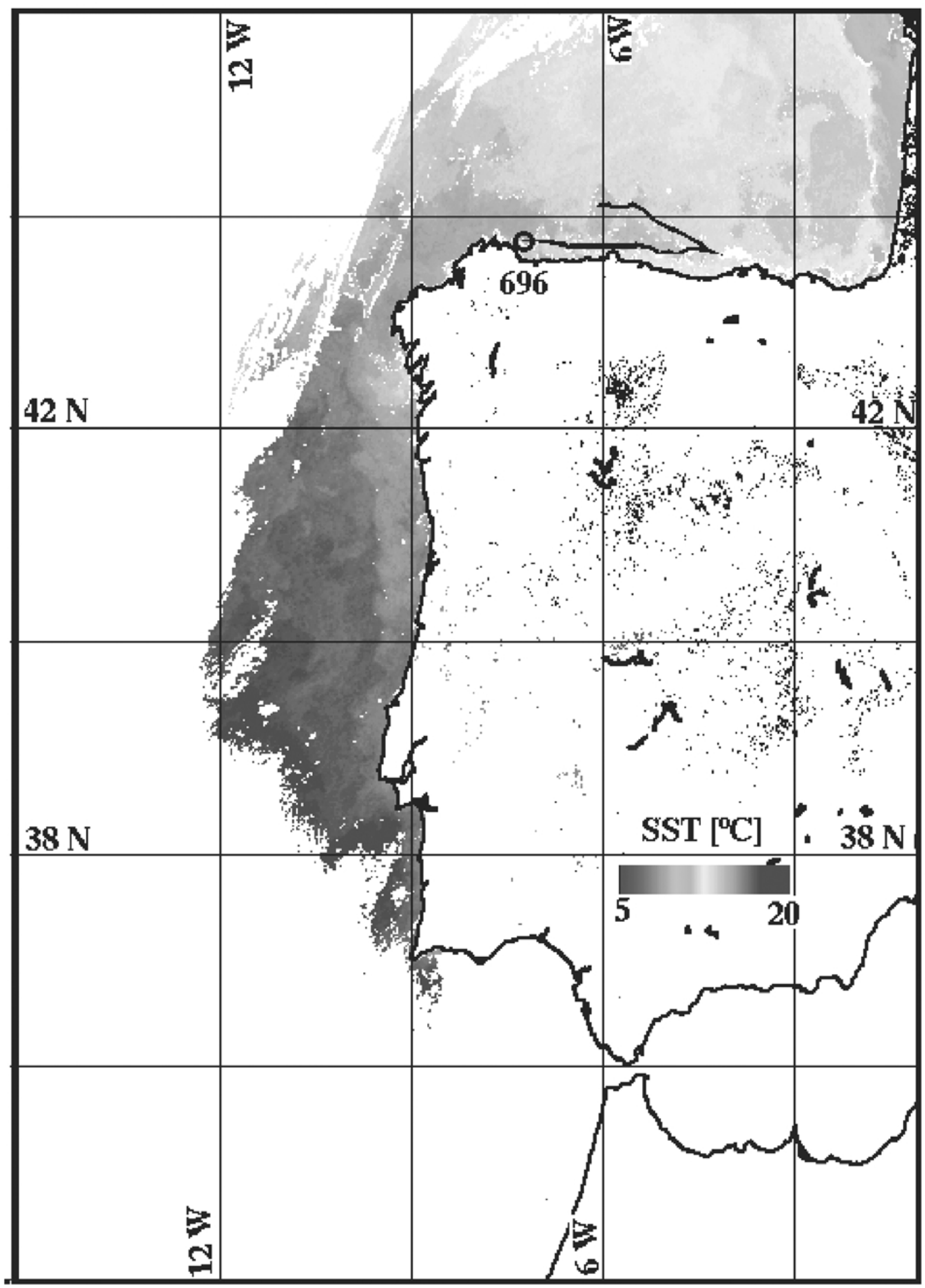

Figure 5. Sea surface temperature (degrees Celsius) from advanced very high resolution radiometer from 18 January 1994. A segment of the trajectory of the drifter 696 between 3 and 29 January 1994 is superimposed. The circle indicates the initial position. See color version of this figure at back of this issue. 
a)

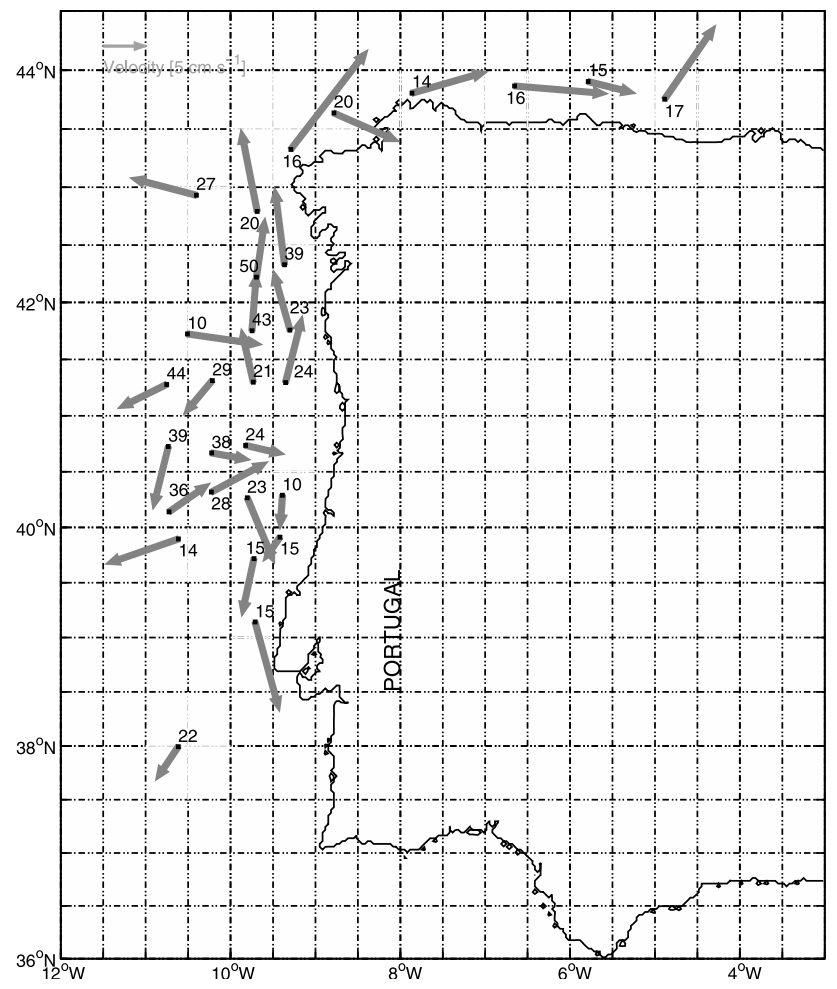

b)

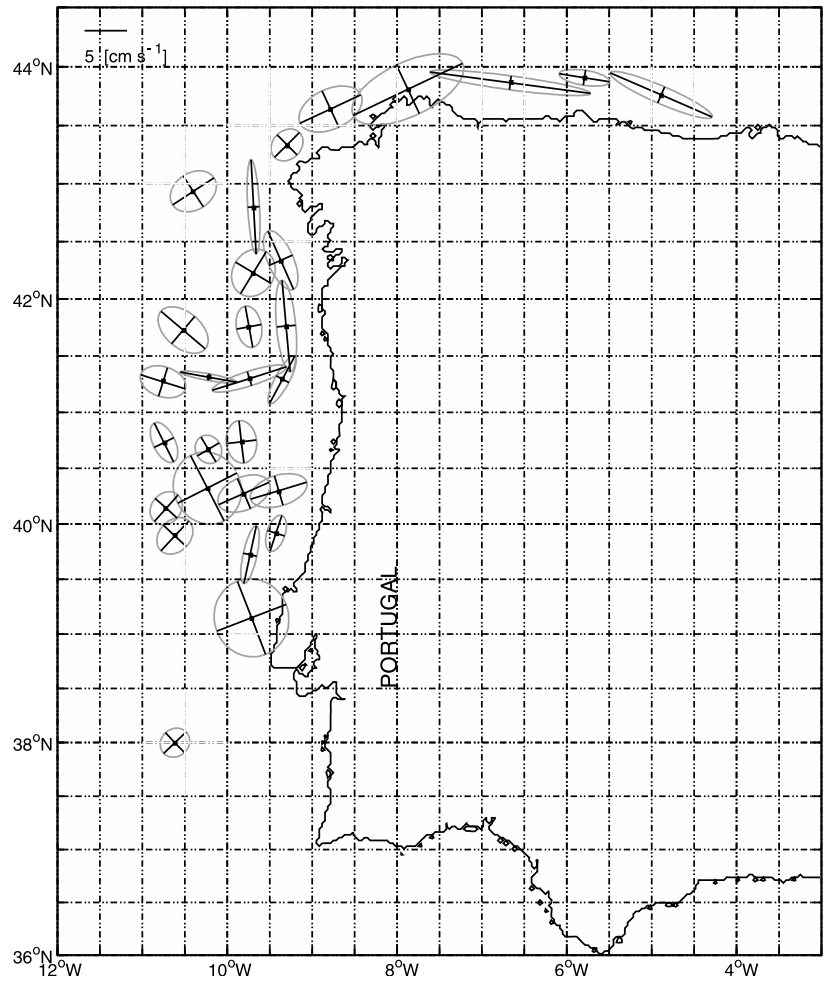

Figure 6. (a) Average velocity field (as in Figure 2) near the Atlantic coast of the Iberian Peninsula. (b) The correspondent directions of variance (as in Figure 2) in boxes of variable geometry in order to improve statistical reliability. have shown that the general trend points to a decrease of EKE from $600 \mathrm{~cm}^{2} \mathrm{~s}^{-2}$ in the North Atlantic Current to 70 $\mathrm{cm}^{2} \mathrm{~s}^{-2}$ near the eastern boundary of the North Atlantic.

[37] The EKE in the PO-SATOCEAN region amounts to $74.9 \pm 19.5 \mathrm{~cm}^{2} \mathrm{~s}^{-2}$, decreasing to $53.0 \pm 15.1 \mathrm{~cm}^{2} \mathrm{~s}^{-2}$ in the MORENA region, confirming the trend of the aforementioned authors. The MKE values are about 4-8 times smaller than the EKE, $14.0 \pm 6.2$ and $9.4 \pm 3.6 \mathrm{~cm}^{2} \mathrm{~s}^{-2}$ for the MORENA and PO-SATOCEAN regions, respectively.

[38] Despite the difficulties, such as the nonsynopticity and nonuniform character of the data, the EKE distribution in Figure 7 suggests a certain homogeneity north of $37^{\circ} \mathrm{N}$ with values of about $50-60 \mathrm{~cm}^{2} \mathrm{~s}^{-2}$. South of $37^{\circ} \mathrm{N}$, higher EKE $\left(100-200 \mathrm{~cm}^{2} \mathrm{~s}^{-2}\right)$ is found in association with the Azores and Canary Currents.

[39] The EKE in the MORENA region is small in comparison to results obtained in other regions of the world ocean, probably because of the presence of the PCC whose MKE is more than twice the EKE, revealing a stable regime. This current is present during the fall, winter, and spring, and this result might be different in the summer when the upwelling prevails with the consequent development of jets and filaments.

[40] The EKE derived from altimetry confirms the distribution patterns obtained from the drifter data set. The maximum levels of EKE are concentrated in the vicinity of the Azores and Canary Currents (Figures 8a and 8b). Differences in the magnitude of the correspondent values could be explained by the fact that the altimetry EKE refers to the geostrophic component of the flow only, while the drifter EKE includes the ageostrophic component of the flow. The EKE obtained from altimetry as well as from surface drifters in the present study is slightly higher compared to the EKE results by Brügge [1995]. However, the author used drifters equipped with drogues located at $100 \mathrm{~m}$. He also identified a tongue of EKE extending eastward near $34^{\circ} \mathrm{N}$, associated with the Azores Current. On the other hand, Ducet et al. [1999] used altimetry data from 1992 to 1997 and stated that the Azores front shows energy ranges from more than $300 \mathrm{~cm}^{2} \mathrm{~s}^{-2}$ at $40^{\circ} \mathrm{W}$ to $150 \mathrm{~cm}^{2} \mathrm{~s}^{-2}$ at $20^{\circ} \mathrm{W}$, which is slightly higher than our results.

[41] Annual maps of EKE (Figure 8b) show reasonable interannual variability, especially in the regions associated with the Azores and Canary Currents, northwest Africa, and south and north Portugal, while the seasonal maps (Figure 8a) show the EKE values rising in fall (October-November-December (OND)), reaching a maximum in winter (January-February-March (JFM)), and decreasing again in spring (April-May-June (AMJ)) toward a minimum in summer (July-August-September (JAS)).

[42] Though the number of buoy days is relatively small in some of the bins located south of $34^{\circ} \mathrm{N}$, both the maps of EKE from altimetry and the drifters show lower values $\left(\sim 50 \mathrm{~cm}^{2} \mathrm{~s}^{-2}\right)$ associated with the PC north of $37^{\circ} \mathrm{N}$ and higher values $\left(100-200 \mathrm{~cm}^{2} \mathrm{~s}^{-2}\right)$ in the region of the Azores and Canary Currents. The maxima in the lee of the Canary Islands and in the vicinity of Madeira Island are probably related to eddies induced by topographic effects. Some of these eddies were also tracked by the drifters (Figures 1 and 9). Though it is only one drifter's trajectory reflecting the EKE maximum near the Canary Islands, the 
satellite-derived EKE also shows maxima of similar magnitude around the Madeira and Canary Islands.

[43] The EKE maximum observed northwest of the Canary Islands might be associated with eddies and meanders. The altimetry EKE include details of the seasonal variability of the currents (Figure $8 \mathrm{~b}$ ). The PCC is evident by maximum EKE along the Iberian coast north of $40^{\circ} \mathrm{N}$ during fall and winter. The Azores Current extends in fall and winter to the vicinity of the Gulf of Cadiz but is weaker in summer and spring, reaching only the longitude of the Canary Islands. However, the interannual variability (Figure 8b) shows a more intense Azores Current reaching the Gulf of Cadiz in 1994/1995.

[44] There seems to be a northward branching of the Azores Current connecting it to the coastal currents along the western Iberian coast. This supports the results of Fiúza et al. [1998], who found a northward flow of Azores Mode Water near the coast of Portugal north of $40^{\circ} \mathrm{N}$. Southward branching of the Azores Current (as given by Klein and Siedler [1989]) near the longitude of Madeira Island is evident in several years and may explain the maximum EKE values found around $21^{\circ} \mathrm{W}$ in the drifter data (Figure 7). The drifters sampled this area during fall but mostly during winter of 1994. Fall and especially winter are the most energetic seasons (Figure 8a), and the EKE from altimetry shows that 1994 was the most energetic year (Figure 8b).

[45] The EKE maps show the Azores front as a meandering intermittent feature, with mesoscale eddies attached and displacing in time. In winter the current meanders strongly and reveals several branches extending southward [Le Traon and De Mey, 1994]. Part of the mesoscale variability may result from the baroclinic instability of the Azores Current [Käse et al., 1985; Kielmann and Käse, 1987; Spall, 1990].

[46] Using historical hydrographic data, Stramma and Siedler [1988] found a smaller north-south extension of the mean front in summer than in winter, with a southward shift of the Azores Current axis of about $2^{\circ}$ in summertime during which the current extends farther east. This can be explained by the reduced meandering in summer. The altimetry EKE fields do not show any southward shift of the front in summer, but the intense fall/winter meandering could be hiding this shift.

\subsection{Characteristics of Eddies}

[47] Lagrangian statistics provide the most direct description of property transport [Davis, 1983], being the most sensitive method to test the validity of eddy-resolving models since Lagrangian measurements involve features of the velocity field important for describing the transport of passive tracers. Eddies and meanders were identified from the drifter trajectories and compared to the AVISO 1/ $4^{\circ}$ mapped altimetry data obtained from TOPEX/Poseidon and ERS-1/2 satellites. Each trajectory was visually examined, and about 70 loops revealed the presence of meanders and eddies (Figure 9). Even single loops reflected the presence of eddies. These were characterized in terms of swirl speed around the eddy center and its translation speed.

[48] The diameter of the loops was estimated by examining each one of the eddies and calculating distances between drifter positions. The number of loops was estimated visually and used to calculate the period of rotation. Average temperature was calculated, as well as the EKE. The results indicate no preference for cyclonic or anticyclonic rotational sense.

[49] The mean translation rate of the eddies was estimated by calculating the mean velocity of each drifter. The characteristic swirl velocity $V_{\theta}$ was estimated as the root mean square velocity of the drifter about its mean velocity [Richardson, 1993]:

$$
V_{\theta}=\left[\overline{u^{\prime 2}}+\overline{v^{\prime 2}}\right]^{1 / 2}
$$

where $u^{\prime}=u-\overline{\mathrm{u}}$, and $v^{\prime}=v-\bar{v}$ represent the zonal and meridional perturbations relative to the mean velocity components $\overline{\mathrm{u}}$ and $\bar{v}$, respectively. Here $\overline{u^{\prime 2}}$ and $\overline{\nu^{\prime 2}}$ are the correspondent variances.

[50] Statistics for groups of loops were calculated considering each loop to give an independent estimate of each of the mentioned quantities. These quantities were averaged from individual estimates. The statistics associated with the eddy characteristics are summarized in Table 3 . The mean values of the velocity components are higher for the anticyclonic vortices, and the results suggest a southwestward migration of the anticyclonic eddies, but a larger amount of data would be required in order to reach a solid conclusion.

[51] The mean timescales and length scales (Table 3) indicate that larger rotation periods are associated with larger eddy diameters. Anticyclonic eddies have larger timescales and length scales than cyclonic ones in the POSATOCEAN area. This tendency reverses in the MORENA area.

[52] The most frequent values of diameters are in the range $9-50 \mathrm{~km}$, with some occurrences in the range $60-$ $100 \mathrm{~km}$ [Martins, 1997]. The correspondent values for the timescales are 6-20 days, and the maximum values in the range 60-80 days are associated with anticyclonic eddies. Table 3 shows that the mean swirl speeds vary in a small range of $9-12 \mathrm{~cm} \mathrm{~s}^{-1}$. Faster swirl speeds are associated with anticyclones $\left(20-24 \mathrm{~cm} \mathrm{~s}^{-1}\right)$. Most values are $10-12$ $\mathrm{cm} \mathrm{s}^{-1}$.

[53] In the MORENA region the EKE calculated only from trajectory segments corresponding to loops is practically the same for cyclonic or anticyclonic eddies (50-60 $\mathrm{cm}^{2} \mathrm{~s}^{-2}$ ), while in the PO-SATOCEAN region the anticyclonic eddies have a higher EKE $\left(82 \mathrm{~cm}^{2} \mathrm{~s}^{-2}\right)$. EKE is in the range $10-100 \mathrm{~cm}^{2} \mathrm{~s}^{-2}$, with the most frequent values in the interval $16-70 \mathrm{~cm}^{2} \mathrm{~s}^{-2}$.

[54] The spatial distribution of the eddy characteristics shows largest diameters $D$ around $35^{\circ}-40^{\circ} \mathrm{N}$, where the Azores and Portugal Currents are found. The results from Table 3 suggest that greater timescales are associated with largest diameters, highest swirl speeds, and highest EKE.

[55] The Rossby number $R o$ was estimated from $R o=$ $2 V_{\theta} /(f D)$ using the observed diameters. $R o \ll 1$, indicating a predominance of the Coriolis acceleration relative to the inertial acceleration, suggesting a quasi-geostrophic equilibrium.

[56] From the temperature data it was not possible to conclude whether cyclonic eddies were colder than anticyclonic eddies nor whether cyclones were colder or anticyclones warmer than the nonloopers. The analysis 

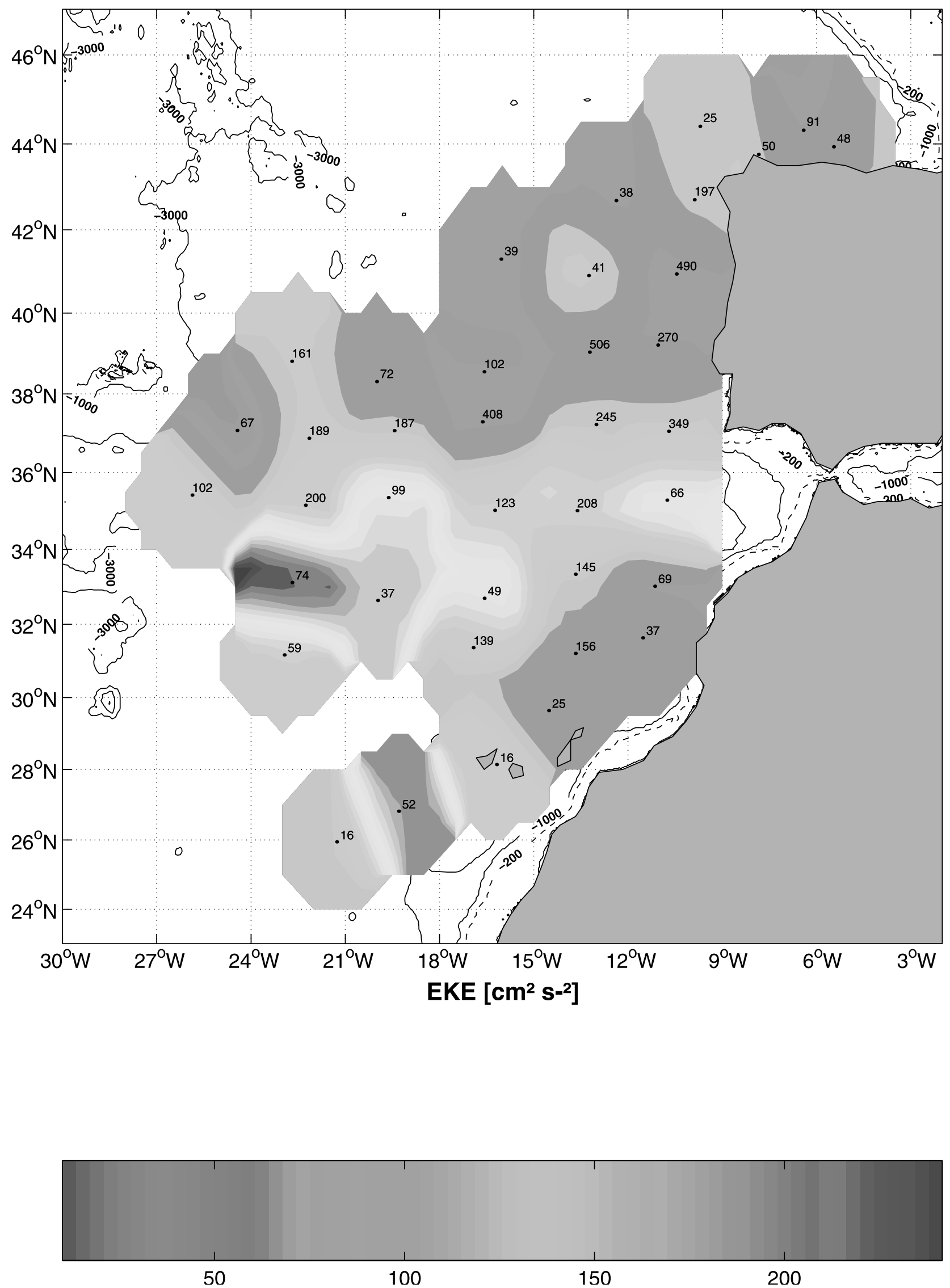

Figure 7. Spatial distribution of EKE $\left(\mathrm{cm}^{2} \mathrm{~s}^{-2}\right)$ from drifter data in boxes of $2^{\circ}$ latitude $\times 3^{\circ}$ longitude. The dots represent the average position of drifters in each box. The number of observations in these bins is indicated. See color version of this figure at back of this issue. 


\section{$\operatorname{EKE}\left[\mathrm{cm}^{2} \mathrm{~s}^{-2}\right]$}
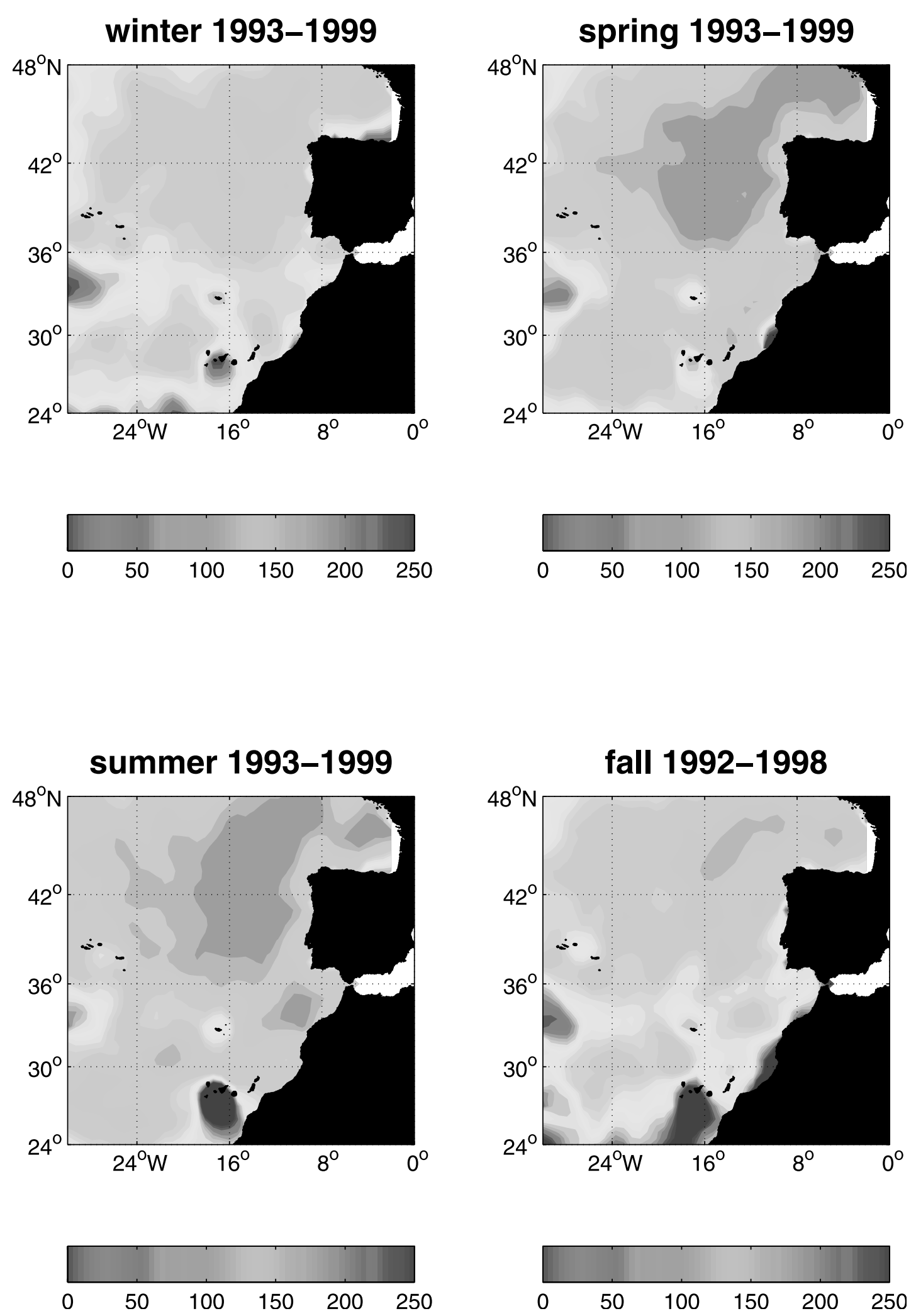

Figure 8a. Seasonal averages of EKE $\left(\mathrm{cm}^{2} \mathrm{~s}^{-2}\right)$ in the northeast Atlantic obtained from altimetry (1992/1993-1999). See color version of this figure at back of this issue. 


\section{EKE $\left[\mathrm{cm}^{2} \mathrm{~s}^{-2}\right]$}

1993
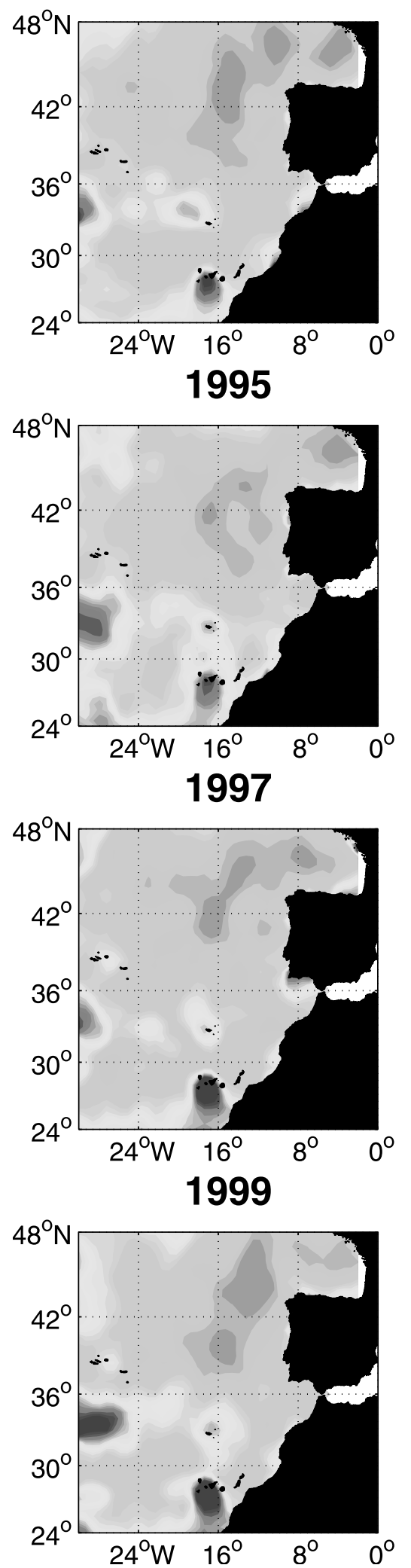

1994
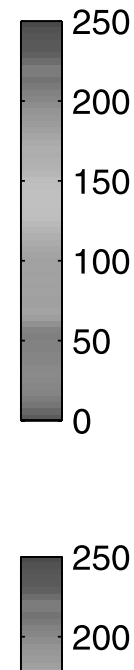

150

100

50
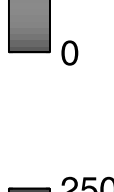

200

150

100

50
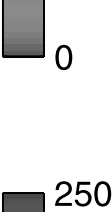

200

150

100

50

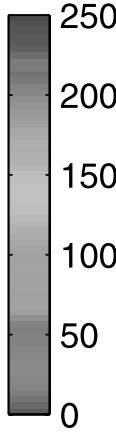

1996
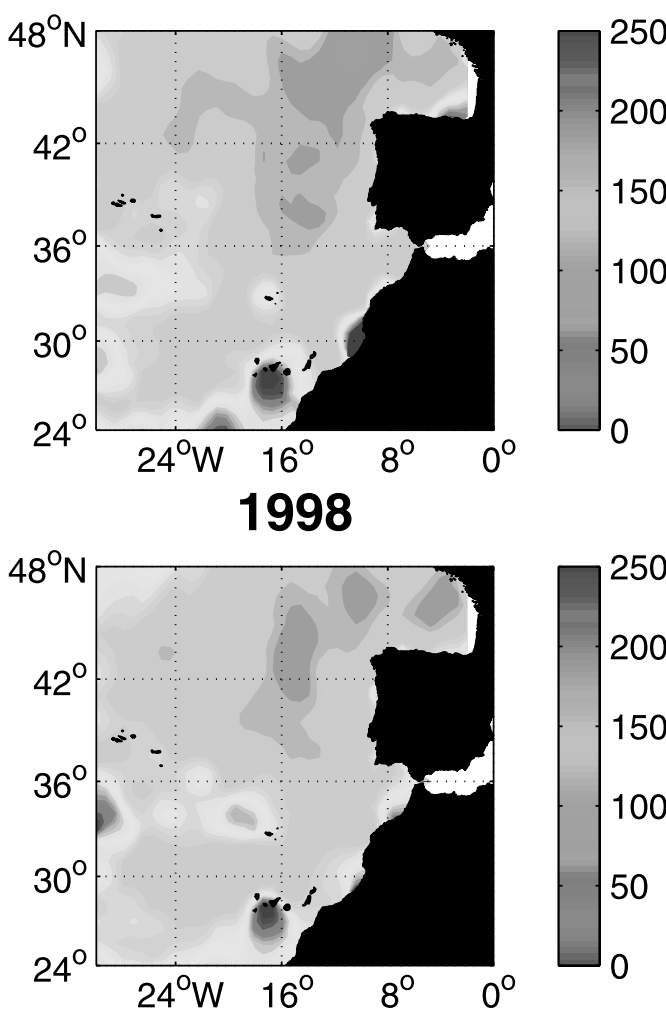

Figure 8b. Annual averages of EKE $\left(\mathrm{cm}^{2} \mathrm{~s}^{-2}\right)$ in the northeast Atlantic obtained from altimetry (1992/ 1993-1999). See color version of this figure at back of this issue. 

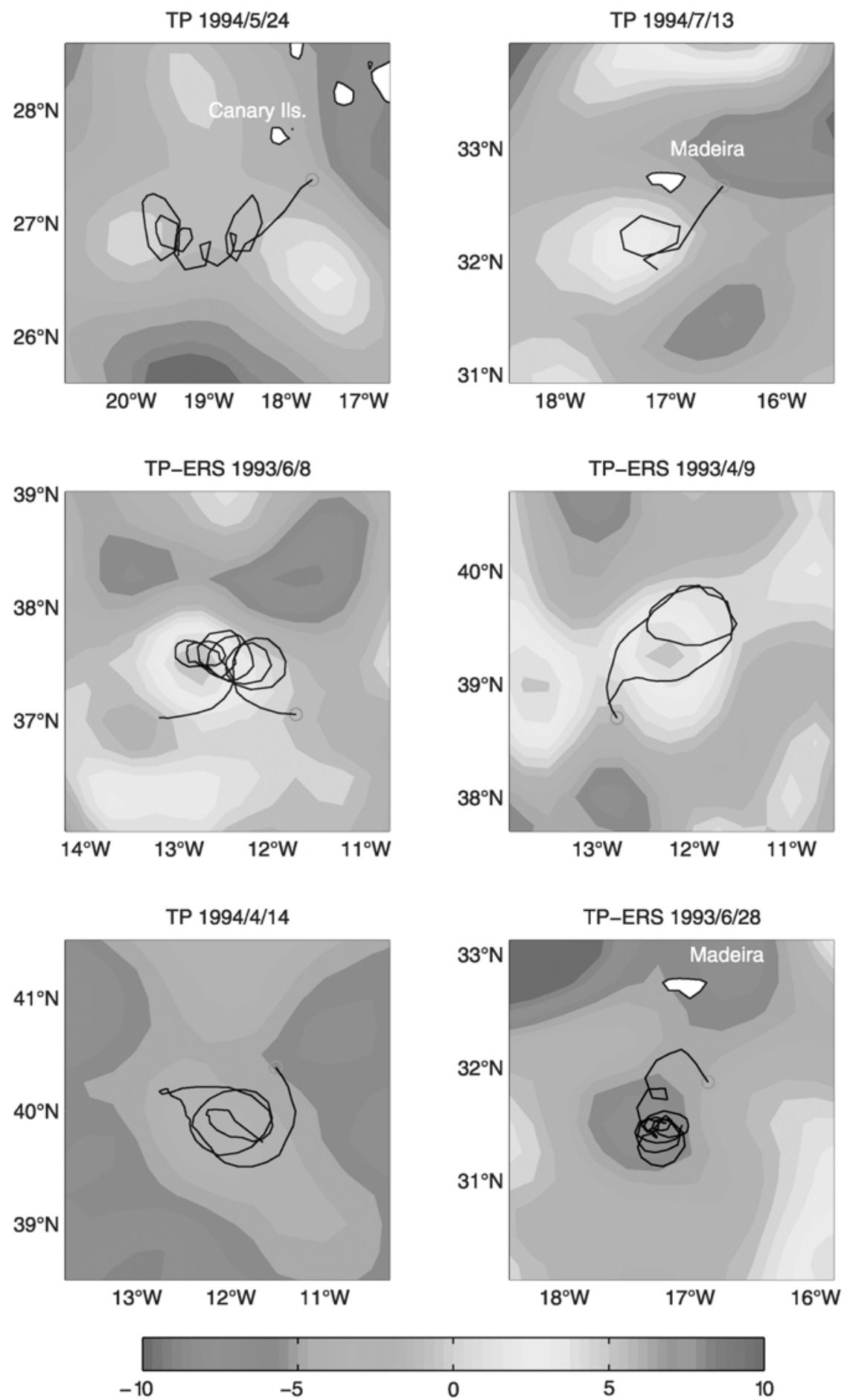

Figure 9. Eddies and meanders observed in the northeast Atlantic using drifter trajectories (black lines) and altimetry sea level anomaly data (centimeters) (colored shading) obtained from ERS and TOPEX/ Poseidon satellites. See color version of this figure at back of this issue.

of the seasonal distribution of the eddy characteristics was inconclusive.

[57] One would probably expect the presence of anticyclonic eddies associated with the PCC near the Iberian Peninsula since the formation and detachment of meanders and eddies in the presence of a poleward current near an eastern boundary would be enhanced by the $\beta$ effect. The instability of a northward eastern boundary current would then predominantly produce meanders and cutoff eddies to the west of the current, and this could explain the predominance of anticyclonic vortices. The eddies found in this region do not allow a confirmation of these expectations. 
Table 3. Eddy Characteristics in Ensemble Regions Corresponding to Cyclonic and Anticyclonic Eddies in the PO-SATOCEAN and MORENA Regions ${ }^{\mathrm{a}}$

\begin{tabular}{|c|c|c|c|c|}
\hline & \multicolumn{2}{|c|}{ MORENA } & \multicolumn{2}{|c|}{ PO-SATOCEAN } \\
\hline & Cyclonic & Anticyclonic & Cyclonic & Anticyclonic \\
\hline$u, \mathrm{~cm} \mathrm{~s}^{-1}$ & 0.3 & -0.9 & -0.4 & -0.9 \\
\hline$v, \mathrm{~cm} \mathrm{~s}^{-1}$ & -0.3 & -0.3 & 0.1 & -0.6 \\
\hline$V_{\theta} \mathrm{cm} \mathrm{s}^{-1}$ & 9.3 & 10.3 & 10.3 & 12.1 \\
\hline$T,{ }^{\circ} \mathrm{C}$ & 17.0 & 14.2 & 17.7 & 17.6 \\
\hline$T_{t}$, days & 18.6 & 13.1 & 15.5 & 22.7 \\
\hline$D, \mathrm{~km}$ & 47.8 & 36.5 & 35.9 & 56.6 \\
\hline EKE, $\mathrm{cm}^{2} \mathrm{~s}^{-2}$ & 50.9 & 56.3 & 58.1 & 81.9 \\
\hline$N$ & 12 & 9 & 22 & 25 \\
\hline
\end{tabular}

a Abbreviations are as follows: translation velocity components, $u$ and $v$; swirl speed, $V_{\theta}$; temperature, $T$; timescales and length scales, $T_{t}$ and $D$; eddy kinetic energy, EKE. and the number of eddies, $N$.

[58] Some of the eddies were found south of the Madeira and Canary Islands. Their origin might be related to a topographic effect on the circulation resulting from the presence of these islands.

[59] Drifter 686, whose trajectory segment is plotted in Figure 9 (date 8 June 1993), followed an anticyclonic eddy west of the Portuguese coast during almost 3 months. Characteristics of this eddy, such as the timescales and length scales of 15 days and $45-50 \mathrm{~km}$, the translation and swirl speeds of about 11 and $12 \mathrm{~cm} \mathrm{~s}^{-1}$, the EKE of $70 \mathrm{~cm}^{2}$ $\mathrm{s}^{-2}$, and the mean temperature of $17^{\circ} \mathrm{C}$, suggest that this might be a surface signature of a meddy [Armi and Zenk, 1984; Pingree and Le Cann, 1993].

[60] The theory [Cushman-Roisin et al., 1990] shows that the eddies tend to migrate westward. As mentioned before, the eddies encountered in the present study do seem to migrate southwestward, but the results require caution in what concerns their statistical significance. The southward component of the eddy motion suggested by the drifter data could also be reflecting the background large-scale circulation in the study area.

\subsection{Lagrangian Statistics and Turbulent Diffusion}

[61] Several authors [Colin de Verdière, 1983; Krauss and Böning, 1987; Poulain and Niiler, 1989; Haynes and Barton, 1991; Swenson and Niiler, 1996] have been comparing the theoretical results of Taylor [1921] for particle dispersion with drifter observations. Their conclusions point to the fact that drifter's dispersion is well modelled by a simple description of the turbulent diffusion, assuming stationary and homogeneous turbulence. Though the number of degrees of freedom of the present data set is not very high, as stated above, the statistics for the Taylor theory calculated in this section is found to be stable.

\subsubsection{Lagrangian Scales of Variability}

[62] The Lagrangian integral timescale $T_{L}$ is one of the properties of the turbulent field and represents a measure of the time over which a particle remembers its path. It is obtained by time $\tau$ integration (to the first zero crossing: $T_{\max }$ ) of the velocity autocovariance function $R$ :

$$
T_{L}=\frac{1}{R(0)} \int_{0}^{T_{\max }} R(\tau) d \tau .
$$

[63] The autocovariance functions were averaged in time for the MORENA and PO-SATOCEAN regions, respec- tively. The correspondent error is computed assuming each trajectory as an independent measure of the timescale. The 28 longest trajectories were used (typically more than 20 days, $\sim 3 T_{L}$ ). The zonal and meridional values of $T_{L}$ (Table 4) are very similar in each region, revealing the isotropic character of the flow. The results show that the decorrelation scale $T_{L}$ in the coastal MORENA region is lower $(3.7 \pm 0.5$ days) than the decorrelation scale in the interior oceanic POSATOCEAN region $(5.1 \pm 0.4$ days $)$, which means that the particles change direction quicker in the MORENA region than in the PO-SATOCEAN region.

[64] The integral timescales have an associated integral length scale $L$. If a random walk regime is assumed, $L$ is related to the distance over which the particle remembers its path by

$$
L=\sqrt{\overline{{\mathrm{u}^{\prime 2}}^{2}} T}
$$

where $\sqrt{\overline{u^{\prime 2}}}$ represents the velocity standard deviation. The resultant ensemble mean values of the Lagrangian length scale $L$ (Table 4 ) were obtained by averaging over each drifter's length scale. In the PO-SATOCEAN region, $L_{u}=$ $44.7 \pm 5.8 \mathrm{~km}$ for the zonal direction, and $L_{v}=35.6 \pm 7.9 \mathrm{~km}$ for the meridional direction. These values correspond to approximately the double of the values obtained in the coastal MORENA area. Again, the length scales reveal the isotropic character of the flow field, especially in the MORENA region, where the particle changes its movement direction in a shorter Lagrangian length scale that is half $(21.7 \pm 6.0 \mathrm{~km})$ of the corresponding value in the POSATOCEAN region $(40.1 \pm 4.8 \mathrm{~km})$. The value of the length scale in the MORENA region $(\sim 20 \mathrm{~km})$ is similar to the internal Rossby deformation radius $\left(R^{\prime}=20-30 \mathrm{~km}\right)$ estimated by Frouin et al. [1990], which gives an indication about the transversal length scale of the poleward PCC.

[65] The zonal and meridional Lagrangian timescales and length scales are represented in Figure 10 as a function of the standard deviation of the correspondent velocity components. The equations of the regression lines are shown as are the correlation coefficients $r$. Figure 10 shows a linear increase of the timescales and length scales with the standard deviation of the velocity.

\subsubsection{Single-Particle Dispersion}

[66] According to Taylor [1921] the single-particle dispersion, i.e., the dispersion of a particle from its origin, is related to the correlation function as

$$
\overline{X^{\prime 2}} t=2 \overline{u^{\prime^{2}}} \int_{0}^{T} \int_{0}^{t} R_{\tau} d \tau d t,
$$

where the bar indicates an ensemble average and $X^{\prime} t$ represents the dispersion of the particle due to $u^{\prime}$. Equation

Table 4. Zonal and meridional ensemble-averaged Lagrangian timescales and length scales and their correspondent errors in the MORENA and PO-SATOCEAN regions ${ }^{\mathrm{a}}$

\begin{tabular}{lcccccc}
\hline \multirow{2}{*}{ Ensemble } & \multicolumn{2}{c}{ Timescale, days } & & \multicolumn{2}{c}{ Length Scale, km } & \\
\cline { 2 - 3 } & Zonal & Meridional & & Zonal & Meridional & $N$ \\
\hline MORENA & $3.7 \pm 0.6$ & $3.6 \pm 0.7$ & & $21.7 \pm 7.7$ & $21.7 \pm 6.4$ & 14 \\
PO-SATOCEAN & $5.5 \pm 0.5$ & $4.6 \pm 0.7$ & & $44.7 \pm 5.8$ & $35.6 \pm 7.9$ & 14 \\
\hline
\end{tabular}

${ }^{\mathrm{a}} \mathrm{N}$ is the number of independent observations. 

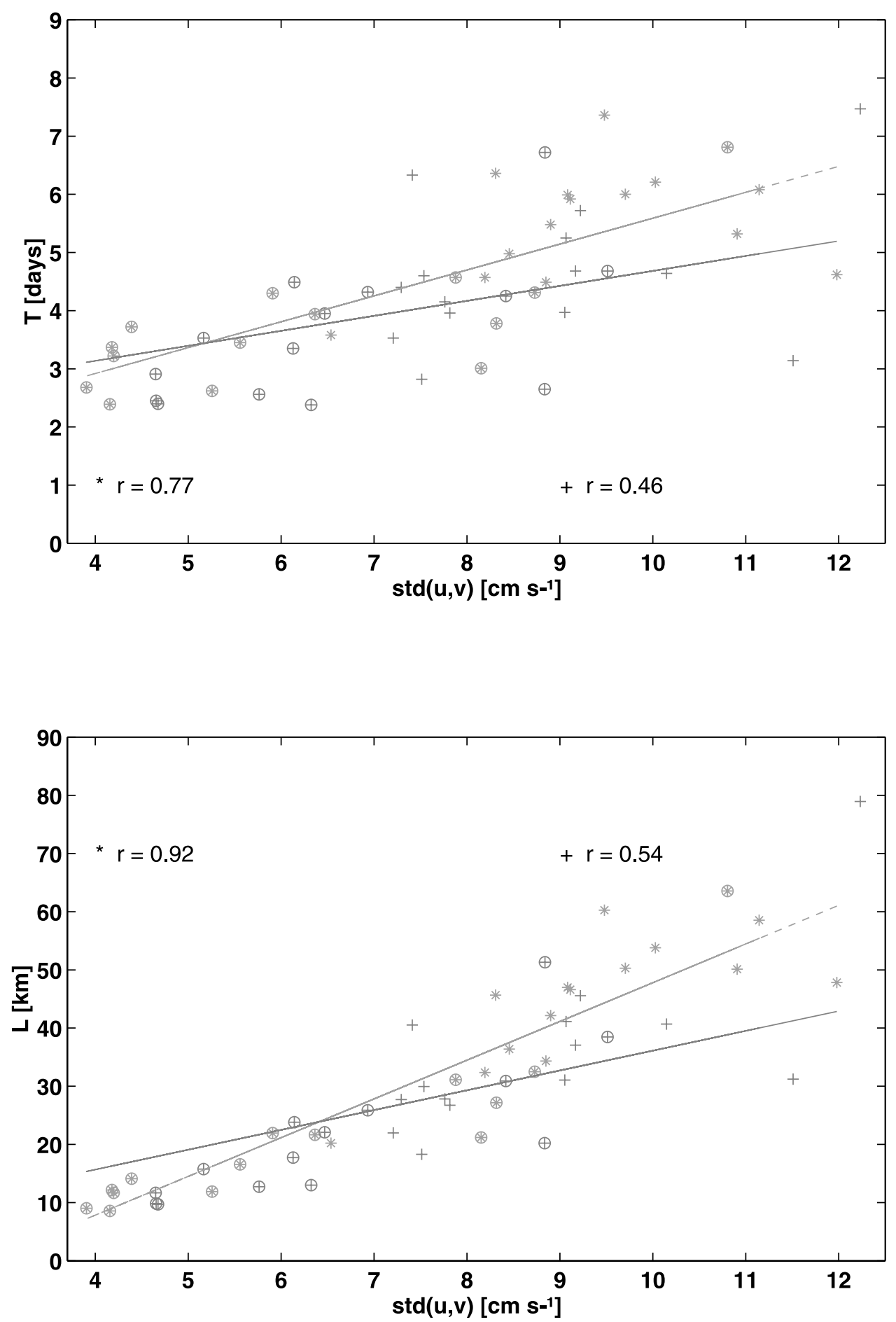

Figure 10. Lagrangian (top) timescales and (bottom) length scales as a function of the standard deviation of the zonal (marked by stars) and meridional (marked by pluses) velocity components. The correspondent linear fits are represented by dashed and solid lines, and their correlation coefficients are also shown. The MORENA values are, furthermore, indicated by circles.

(7) reduces the problem of diffusion to a simplified type of turbulent motion to the consideration of a single quantity, namely, the correlation coefficient between the velocity of a particle at one instant and that at a time $\tau$ later.
[67] Considering the asymptotic limits of equation (7):

Initial dispersion

$$
t \rightarrow 0\left(t<T_{L}\right),\left[\sqrt{\overline{X^{\prime 2}}}\right]=\sqrt{\overline{u^{\prime 2}}} t,
$$



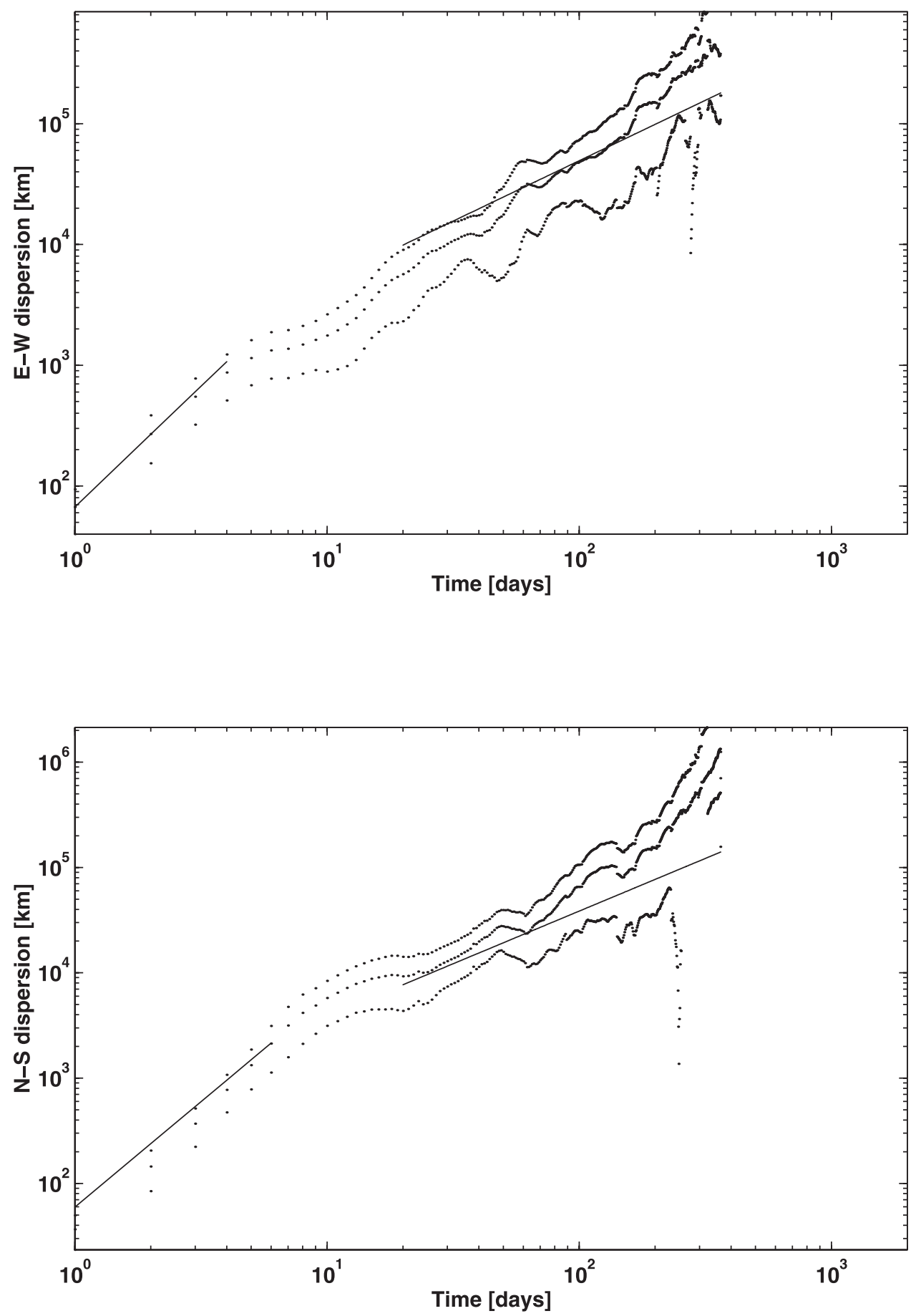

Figure 11. The drifters' dispersion as a function of time in a logarithmic scale. The straight lines represent the results of Taylor's [1921] theory. The dots represent the observations and corresponding errors $(95 \%)$.

Random walk regime

$$
t \gg T_{L},\left[\sqrt{\overline{X^{\prime 2}}}\right]=\sqrt{2 T_{L} \overline{t u^{\prime 2}}},
$$

so that $\overline{X^{\prime 2}}$ increases at a uniform rate, a property that is analogous to the properties of discontinuous random migration in one dimension. For small time intervals $t<$ $T_{L}, \overline{X^{\prime 2}}$ increases with $t^{2}$, while as $t$ increases and becomes larger than $T_{L}$, the particle dispersion changes from a quadratic to a linear dependence on time; that is, the dispersion process slows down to a random process. Figure 11 illustrates the drifter's dispersion obtained from the residual speed as a function of time, showing a good adjustment between the theory (straight lines in Figure 11) and the observed dispersion for the zonal and meridional directions.

\subsubsection{Eddy Diffusivity}

[68] The relation between the diffusivity, the velocity fluctuations, and the dispersive properties of the turbulent 
Table 5. Zonal and Meridional Ensemble Eddy Diffusivities for the PO-SATOCEAN and MORENA Regions and the Correspondent Errors ${ }^{\mathrm{a}}$

\begin{tabular}{cccc}
\hline & \multicolumn{3}{c}{ Diffusivity $\left(\times 10^{7} \mathrm{~cm}^{2} \mathrm{~s}^{-1}\right)$} \\
\cline { 2 - 4 } Ensemble & Zonal & Meridional & $N$ \\
\hline MORENA & $1.6 \pm 0.9$ & $1.6 \pm 0.7$ & 14 \\
PO-SATOCEAN & $4.3 \pm 0.8$ & $3.3 \pm 1.1$ & 14 \\
\hline
\end{tabular}

${ }^{\mathrm{a}} \mathrm{N}$ is the number of independent observations.

field was presented by Taylor [1921]. The dispersion of particles can be parameterized as an eddy diffusivity $K(t)$ through

$$
K_{i i}=\frac{1}{2} \frac{d}{d t} \overline{X_{i}^{\prime 2}(t)}=\overline{u^{\prime 2}} \int_{0}^{t} R\left(t^{\prime}\right) d t^{\prime} .
$$

The Lagrangian diffusivity provides a measure of the rate of spreading of a particle from its initial position, which gives the rate of change of the root mean square particle position relative to the mean trajectory of the particle. $K$ is computed from the normalized autocovariance functions $R$, and therefore the diffusivities are expected to tend asymptotically to a constant value, the saturation value, after some integral timescales $T_{L}$.

[69] Analyzing the asymptotic limits for $t \gg T_{L}$, the random walk regime, the dispersion is proportional to time $t$ and the diffusion coefficient is

$$
K_{i i}=\overline{u_{i}^{\prime 2}} T_{L}=L\left[\overline{u_{i}^{\prime 2}}\right]^{1 / 2} ;
$$

that is, it is given by the product between the intensity of turbulence and the Lagrangian length scale. The rate of dispersion depends on the scales of the dominant processes.

[70] The diffusivity values computed using equation (11) in the MORENA region are lower $\left(K=(1.6 \pm 0.7) 10^{7} \mathrm{~cm}^{2}\right.$ $\left.\mathrm{s}^{-1}\right)$ than the ones in the PO-SATOCEAN region $(K=(3.8$ $\left.\pm 0.7) 10^{7} \mathrm{~cm}^{2} \mathrm{~s}^{-1}\right)$. The zonal and meridional values shown in Table 5 reveal the isotropic character of the flow field, particularly in the MORENA area. The values in this region reduce to about one third and one half of the correspondent diffusivities in the PO-SATOCEAN region.

[71] For the particle dispersion study a relatively large number of realizations is required. Considering the hypotheses of a stationary homogeneous flow, the number of degrees of freedom was incremented [Martins, 1997] using a method first described by Colin de Verdière [1983]: once the decorrelation timescales vary between a few days and about a week, each two positions separated by a time interval larger than the Lagrangian timescale are decorrelated. Reinitializing the trajectories of the drifters each 10 days is a possible way of increasing the degrees of freedom. This procedure allocates too much emphasis on the intermediate portions of each trajectory, which is the most frequently sampled by this segmentation process, and may constitute a disadvantage if the temporal series are very short. However, we expect the risk of introducing a tendency in the Lagrangian statistics to be compensated by the increase of degrees of freedom.

[72] Using the whole data set of the reinitialized trajectories and the relation (11), the cumulative ensemble mean value of $K$ was recomputed, and the results for the zonal and meridional directions are represented in Figure 12. The diffusivity increases rapidly in the initial phase, reaching a plateau after about $20-30$ days. The mean values in the POSATOCEAN region for $t>50$ days and until about 250 days, corresponding to the random walk regime, are $K=(2.4 \pm$ $0.4) 10^{7} \mathrm{~cm}^{2} \mathrm{~s}^{-1}$, with $K_{u u}=(2.8 \pm 0.1) 10^{7} \mathrm{~cm}^{2} \mathrm{~s}^{-1}$ and $K_{v v}=$ $(2.1 \pm 0.1) 10^{7} \mathrm{~cm}^{2} \mathrm{~s}^{-1}$ for the east-west and north-south directions, respectively. In the MORENA region the correspondent values for $t>50$ days and until about 180 days are $K=(1.3 \pm 0.2) 10^{7} \mathrm{~cm}^{2} \mathrm{~s}^{-1}, K_{u u}=(1.5 \pm 0.1) 10^{7} \mathrm{~cm}^{2} \mathrm{~s}^{-1}$, and $K_{v v}=(1.0 \pm 0.1) 10^{7} \mathrm{~cm}^{2} \mathrm{~s}^{-1}$. In this regime of random walk the zonal diffusivity is larger than the meridional diffusivity by a factor of about 1.5 for the MORENA region and about 1.3 for the PO-SATOCEAN region. It is possible that the spatial inhomogeneity plays a role since longer trajectories tend to sample different flows in statistical terms, and as mentioned above, the weights on the trajectory segments vary. This may be the reason for the slightly smaller values of $K$ in the PO-SATOCEAN region than the ones presented in Table 5. The number of observations in the PC is higher than in the Canary and Azores Currents, thus leading to the oversampling of that current as mentioned above (see also Figure 7 for low EKE in the PC). The number of observations decreases in time, leading to an increase on the standard deviation of the diffusivity (Figure 12).

[73] The slow variation of $K$ for longer times may originate in a weak long-term variability associated with the current system in the study area. The existence of spatial inhomogeneity is the reason for truncating the covariance [Davis, 1991] at a finite interval $t$, in which these errors are still small. The confidence with which an advection-diffusion model can be applied using an asymptotic value for $K$ is related to the rapidity with which $K$ reaches a stable value. Using this asymptotic value, the model should adequately describe the evolution of fields of passive tracers, such as the large-scale ocean temperature, allowing an access to the turbulence.

[74] The eddy diffusivity is plotted against the EKE in Figure 13, comparing to results from other authors. The eddy diffusivity is in fact larger where EKE values are higher. The linear fit through all data presented in Figure 13 results in the relation $K=9.6 \times 10^{6}+3.2 \times 10^{5} \mathrm{EKE}$, and the correlation coefficient is 0.7 . This relation suggests a timescale of 3.7 days, in accordance with the results previously obtained using the autocovariance functions (Table 4). The diffusivity variation pattern seems to indicate an increase of this quantity from the Iberian coast toward the ocean interior and the regions of the Azores and Canary Currents.

\subsection{Velocity-Temperature Statistics}

[75] The temperature data set corresponds to about $95 \%$ (5000 drifter data days) of the whole data set and is used to estimate the eddy diffusivity in the zonal $\left(K_{x}\right)$ and meridional $\left(K_{y}\right)$ directions in the study region. The 24 hour averages $(\bar{u}, \bar{v}$, and $\bar{T})$ of the zonal $(u)$ and meridional $(v)$ components and temperature $(T)$ were used, as well as the perturbations about the mean, $u^{\prime}=u-\overline{\mathrm{u}}, v^{\prime}=v-\bar{v}$, and $T^{\prime}=$ $T-\bar{T}$, and the equations

$$
K_{x}=\frac{\overline{T^{\prime} u^{\prime}}}{d T / d x} \quad K_{y}=\frac{\overline{T^{\prime} \nu^{\prime}}}{d T / d y} .
$$



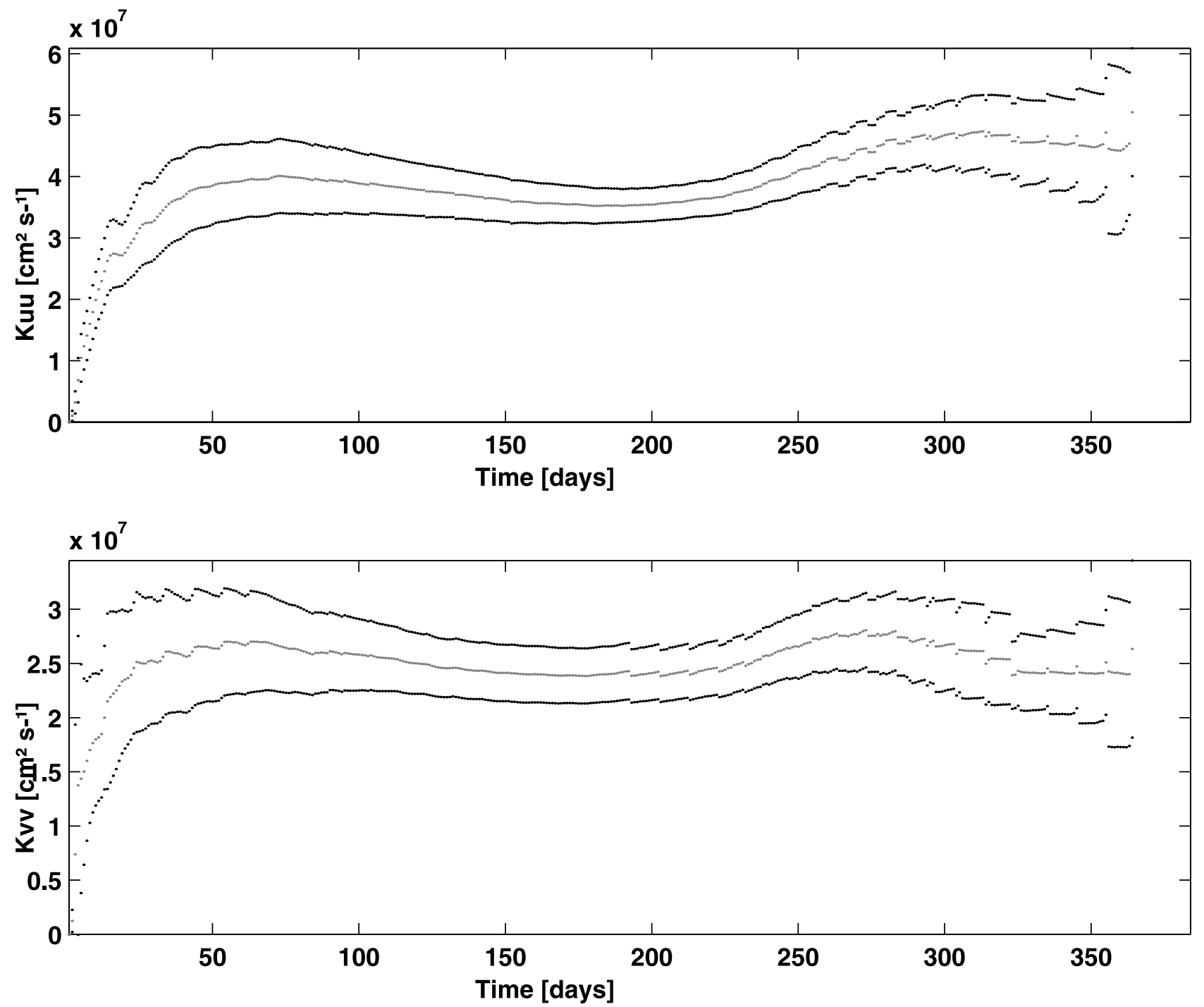

Figure 12. (top) Zonal and (bottom) meridional eddy diffusivity plotted against time. The surrounding lines of dots represent the corresponding errors (95\%).

Here $d T / d x$ and $d T / d y$ were estimated considering the drifter positions and temperatures. With $d T / d x=4.5 \times 10^{-4 \circ} \mathrm{C}$ $\mathrm{m}^{-1}, d T / d y=4.8 \times 10^{-4 \circ} \mathrm{C} \mathrm{m}^{-1}, d T / d x=4.3 \times 10^{-4 \circ} \mathrm{C}$ $\mathrm{m}^{-1}$, and $d T / d y=8.9 \times 10^{-4 \circ} \mathrm{C} \mathrm{m}^{-1}$ the obtained values are: $K_{x S}=4.5 \times 10^{7} \mathrm{~cm}^{2} \mathrm{~s}^{-1}, K_{y S}=2.6 \times 10^{7} \mathrm{~cm}^{2} \mathrm{~s}^{-1}, K_{x M}$ $=2.6 \times 10^{7} \mathrm{~cm}^{2} \mathrm{~s}^{-1}$, and $K_{y M}=2.8 \times 10^{7} \mathrm{~cm}^{2} \mathrm{~s}^{-1}$ for the PO-SATOCEAN and MORENA regions, respectively.

[76] The comparison of these results with the eddy diffusivities computed from particle statistics reveals that $K_{x}$ and $K_{y}$ are in accordance with the eddy diffusivities obtained from Taylor's [1921] theory (Table 5), supporting the diffusivity estimates resulting from this theory. Differences between the values of $K$ are due to the rough estimate done here. However, the order of magnitude agrees well. These values of eddy diffusivity could be used to estimate the horizontal eddy heat flux divergence.

\section{Summary and Conclusion}

[77] The present study aimed at a description of the surface circulation in the northeast Atlantic region located between the Iberian Peninsula, the Azores, and the Canary Islands using satellite-tracked drifters. It was not only possible to describe the currents qualitatively but also quantitatively using Eulerian averages in geographic bins. The mean velocity field reproduces the main currents in the study region: (1) the Portugal Current, a slow and variable southward large-scale surface circulation between continental Portugal and the Azores; (2) the Portugal Coastal Countercurrent, a poleward current north of $41^{\circ} \mathrm{N}$ along the west and north coasts of the Iberian Peninsula during the fall, winter, and early spring; (3) the southward Portugal Coastal Current, an equatorward current along the west coast of Portugal south of $41^{\circ} \mathrm{N}$; (4) the Azores Current, a zonal eastward current between $34^{\circ}$ and $36^{\circ} \mathrm{N}$ extending into the Gulf of Cadiz; and (5) the Canary Current, a southward current along the west African coast near the Canary Islands. The drifter trajectories show the confluence of the Portugal and Azores Currents into the Canary Current being part of the eastern recirculation of the subtropical gyre.

[78] The eddy kinetic energy maximum values are associated with the main currents in the region. The energy 


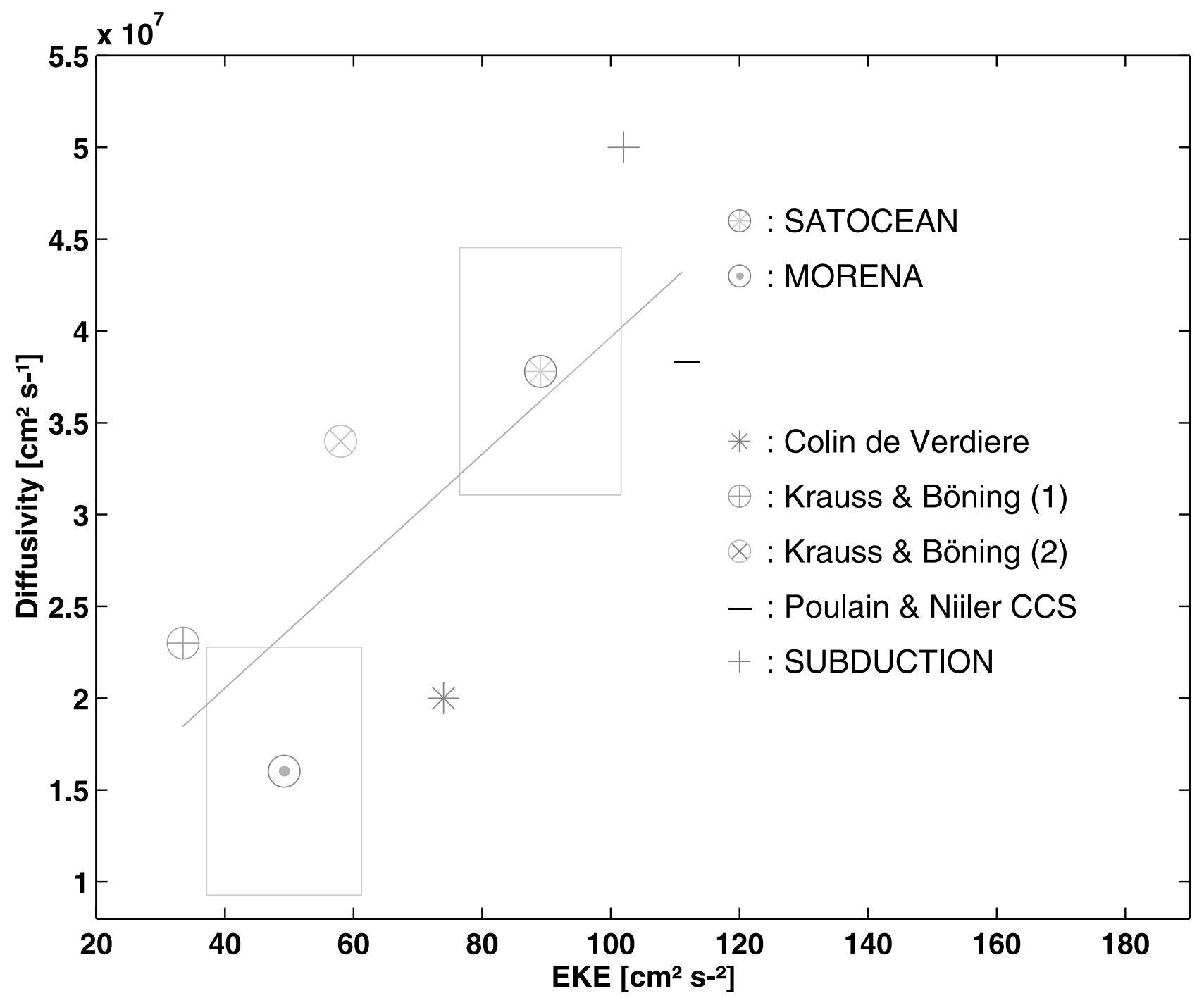

Figure 13. Eddy diffusivity as a function of the EKE. Results from the present study and from other authors are presented. The boxes represent the error of the mean values for the MORENA and POSATOCEAN regions. The best linear fit is also shown.

increases westward and southward toward the Azores and Canary Currents. The EKE field undergoes considerable interannual variability, shows higher values during the winter season, and is the largest contribution to the total kinetic energy.

[79] The drifter data set is analyzed aiming at a description of the eddy characteristics in the study region. There is no preferential rotation sense. The swirl speed has a relatively small variation range, $9-12 \mathrm{~cm} \mathrm{~s}^{-1}$. Timescales and length scales are $O(10$ days $)$ and $O(10 \mathrm{~km})$. The eddies observed near the Iberian coast might not have an intense role in the dispersion at long temporal scales but might introduce a shear effect contributing to the mixing. The eddy kinetic energy is very similar for the cyclonic eddies over the whole study region and anticyclonic eddies in the MORENA region, while the anticyclonic eddies in the POSATOCEAN region are about 1.5 times more energetic. There is a tendency for higher mean translation speeds for anticyclones, with higher velocities in the westward and southward directions. This prevailing southwestward move- ment could be related to the reported tendency of the eddies to move westward because of the conservation of potential vorticity [Freeland et al., 1975], but the southward eddy translation could also be reflecting the large-scale southward flow in the region.

[80] Classical Lagrangian single-particle statistics were computed for the MORENA and PO-SATOCEAN ensembles of drifters. The average integral Lagrangian timescales and length scales and the eddy diffusivities increase toward the ocean interior. The particles change their movement direction in shorter timescales and length scales in the MORENA region than in the PO-SATOCEAN region.

[81] The mean diffusivities are found to have an approximately linear relation with the eddy kinetic energy. A good agreement was obtained between the observations and the classical Taylor's [1921] theory for the turbulent diffusion by homogeneous and random motions. Apparently, at a firstorder approximation the idea of a homogeneous and stationary velocity field is consistent. The results published by several other authors in different oceanic regimes lead to the 
conclusion that dispersion of a tracer at the ocean surface is well described by an isotropic advection-diffusion model.

[82] Acknowledgments. This work was carried out within the NATO PO-SATOCEAN and MORENA projects, which were funded by NATO (Science for Stability Programme) and by the European Union MAST II Programme under contract MAS2-CT93-0065. The work was supported by the Portuguese Science Foundation (JNICT) through the CIRPOR and FLUXPOR/94 projects and a PALOP (African Countries of Portuguese Language) programme grant. Thanks are due to the officers and crew members of the vessel Corvo as well as to the company owning this ship, Mutualista Açoreana, to the administration of the Port of Ponta Delgada, to all the members of the scientific team, and to the officers and crew members of R/Vs Håkon Mosby (NERSC-Norway), Cornide de Saavedra (IEOSpain), and Noruega (IPIMAR) for helping with the deployment of the drifters. Special thanks are due to the two anonymous reviewers who helped considerably to improve the manuscript.

\section{References}

Armi, L., and W. Zenk, Large lenses of highly saline Mediterranean Water, J. Phys. Oceanogr., 14, 1560-1576, 1984

Brügge, B., Near-surface mean circulation and kinetic energy in the central North Atlantic from drifter data, J. Geophys. Res., 100, 20,543-20,554, 1995.

Colin de Verdière, A., Lagrangian eddy statistics from surface drifters in the eastern North Atlantic, J. Mar. Res., 41, 375-398, 1983.

Cushman-Roisin, B., E. P. Chassignet, and B. Tang, Westward motion of mesoscale eddies, J. Phys. Oceanogr., 20, 758-768, 1990.

Davis, R. E., Oceanic property transport, Lagrangian particle statistics, and their prediction, J. Mar. Res., 41, 163-194, 1983.

Davis, R. E., Drifter observations of coastal surface currents during CODE: The statistical and dynamical views, J. Geophys. Res., 90, 4756-4772, 1985.

Davis, R. E., Observing the general circulation with floats, Deep Sea Res., 38, suppl. 1, S531-S571, 1991.

Ducet, N., P. Y. Le Traon, and G. Reverdin, How accurately can we map the mesoscale ocean surface variability from the combination of $\mathrm{T} / \mathrm{P}$ and ERS-1/2 altimetric data, Int. WOCE Newsl., 37, 40-43, 1999.

Fiúza, A. F. G., M. E. Macedo, and M. R. Guerreiro, Climatological space and time variation of the Portuguese Coastal Upwelling, Oceanol. Acta, $5,31-40,1982$.

Fiúza, A. F. G., M. Hamann, I. Ambar, G. Díaz, N. González, and J. Cabanas, Water masses and their circulation off western Iberia during May 1993, Deep Sea Res., Part II, 45, 1127-1160, 1998.

Freeland, H., P. Rhines, and T. Rossby, Statistical observations of the trajectories of neutrally buoyant floats in the North Atlantic, J. Mar. Res., 33, 383-404, 1975

Frouin, R., A. F. G. Fiúza, I. Ambar, and T. J. Boyd, Observations of a poleward surface current off the coast of Portugal and Spain during winter, J. Geophys. Res., 95, 679-691, 1990.

Haynes, R., and E. D. Barton, A poleward flow along the Atlantic coast of the Iberian Peninsula, J. Geophys. Res., 95, 11,425-11,441, 1990.

Haynes, R., and E. D. Barton, Lagrangian observations in the Iberian Coastal Transition Zone, J. Geophys. Res., 96, 14,731-14,741, 1991.

Käse, R. H., W. Zenk, T. B. Sanford, and W. Hiller, Currents, fronts and eddy fluxes in the Canary Basin, Prog. Oceanogr., 14, 231-257, 1985.

Kielmann, J., and R. H. Käse, Numerical modeling of meander and eddy formation in the Azores Current Frontal Zone, J. Phys. Oceanogr, 17, 529-541, 1987.
Klein, B., and G. Siedler, On the origin of the Azores Current, J. Geophys. Res., 94, 6159-6168, 1989.

Krauss, W., and C. W. Böning, Lagrangian properties of eddy fields in the northern North Atlantic as deduced from satellite-tracked buoys, J. Mar. Res., 45, 259-291, 1987.

Krauss, W., and R. H. Käse, Mean circulation and eddy kinetic energy in the eastern North Atlantic, J. Geophys. Res., 89, 3407-3415, 1984.

Le Traon, P. Y., and P. De Mey, The eddy field associated with the Azores Front east of the Mid-Atlantic Ridge as observed by the Geosat, J. Geophys. Res., 99, 9907-9923, 1994.

Martins, C. S., Estudo da circulação oceânica superficial no Atlântico Nordeste utilizando bóias derivantes com telemetria por satélite, Ph.D. thesis, Univ. de Lisboa, Lisbon, Portugal, 1997.

McCreary, J. P., S. R. Shetye, and P. K. Kundu, Thermohaline forcing of eastern boundary currents: With application to the circulation off the west coast of Australia, J. Mar. Res., 44, 71-92, 1986.

McCreary, J. P., P. K. Kundu, and S.-Y. Chao, On the dynamics of the California Current System, J. Mar. Res., 45, 1-32, 1987.

Niiler, P. P., and J. D. Paduan, Wind-driven motions in the northeast Pacific as measured by Lagrangian drifters, J. Phys. Oceanogr., 25, 2819-2830, 1995.

Pingree, R. D., and B. Le Cann, A shallow meddy (a SMEDDY) from the secondary Mediterranean salinity maximum, J. Geophys. Res., 98, 20,169-20,185, 1993.

Pollard, R. T., and S. Pu, Structure and circulation of the upper Atlantic Ocean northeast of the Azores, Prog. Oceanogr., 14, 443-462, 1985.

Poulain, P. M., and P. P. Niiler, Statistical analysis of the surface circulation in the California Current System using satellite-tracked drifters, J. Phys. Oceanogr., 19, 1588-1603, 1989.

Richardson, P. L., Eddy kinetic energy in the North Atlantic from surface drifters, J. Geophys. Res., 88, 4355-4367, 1983.

Richardson, P. L., A census of eddies observed in North Atlantic. SOFAR float data, Prog. Oceanogr., 31, 1-50, 1993.

Spall, M. A., Circulation in the Canary Basin: A model/data analysis, $J$. Geophys. Res., 95, 9611-9628, 1990.

Stramma, L., Geostrophic transport in the warm water sphere of the eastern subtropical North Atlantic, J. Mar. Res., 42, 537-558, 1984.

Stramma, L., and G. Siedler, Seasonal changes in the North Atlantic subtropical gyre, J. Geophys. Res., 93, 8111-8118, 1988.

Swenson, M. S., and P. P. Niiler, Statistical analysis of the surface circulation of the California Current, J. Geophys. Res., 101, 22,631-22,645, 1996.

Sy, A., Investigation of large-scale circulation patterns in central North Atlantic: The North Atlantic Current, the Azores Current and the Mediterranean Water plume in the area of the Mid-Atlantic Ridge, Deep Sea Res., Part A, 35, 383-413, 1988.

Taylor, G. I., Diffusion by continuous movements, Proc. London Math. Soc., 20, 196-212, 1921.

Wooster, W. S., A. Bakun, and D. R. McLain, The seasonal upwelling cycle along the eastern boundary of the North Atlantic, J. Mar. Res., 34, $131-$ $141,1976$.

C. Sena Martins and M. Hamann, Institut für Meereskunde, Universität Kiel, Düstenbrooker Weg 20, D-24105 Kiel, Germany. (csena@ifm.uni-kiel.de; mhamann@ifm.uni-kiel.de)

A. Fiúza, Instituto de Oceanografia, Universidade de Lisboa, R. Ernesto Vasconcelos, (Campo Grande), 1749-016 Lisboa, Portugal. (fiuza@fc.ul.pt) 


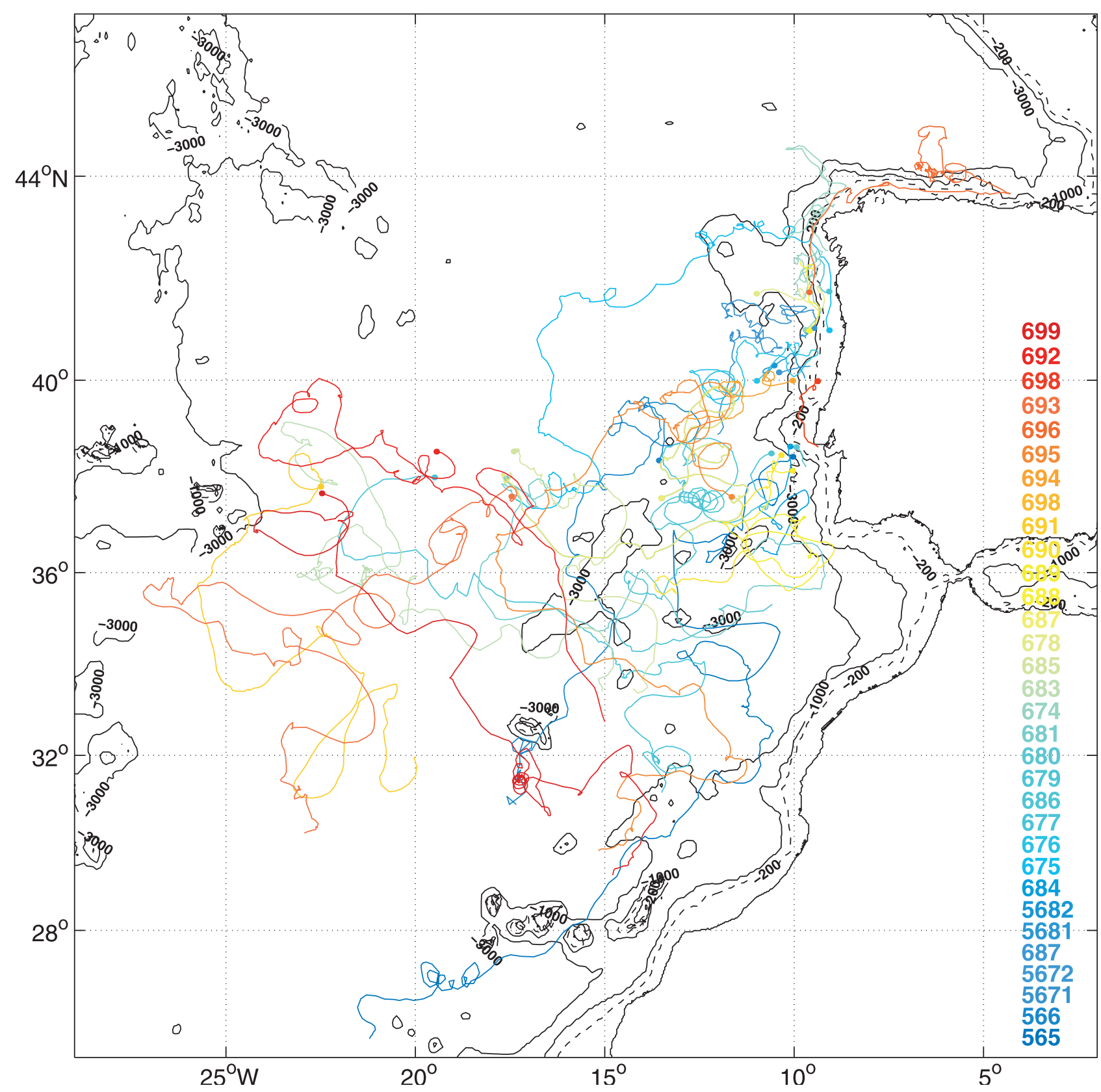

Figure 1. WOCE-TOGA surface $(15 \mathrm{~m})$ drifter trajectories between January 1993 and October 1994. The drifter identification numbers are indicated on the right; the color corresponds to the color of the trajectory. The starting point is indicated by a dot in the same color. 


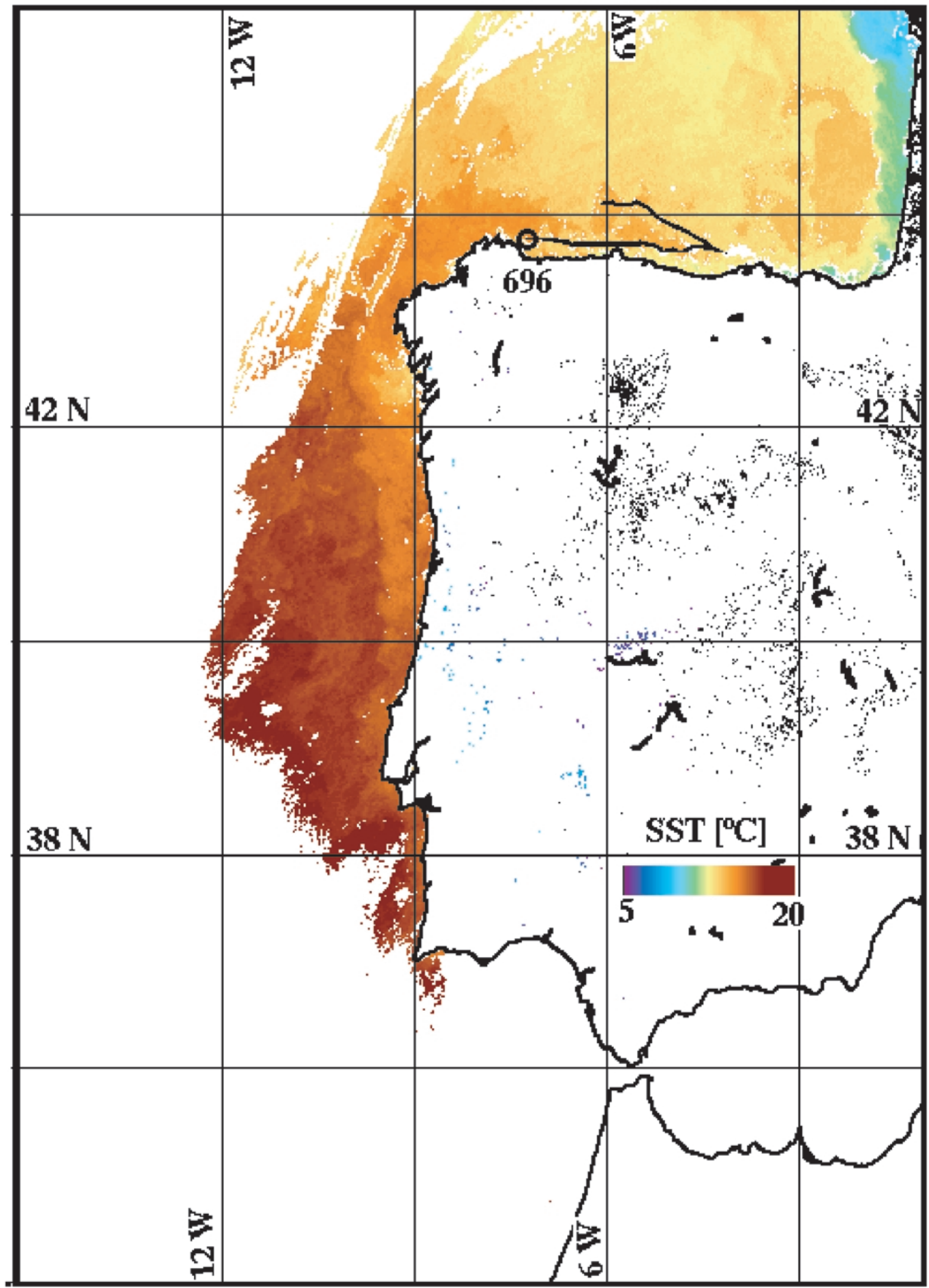

Figure 5. Sea surface temperature (degrees Celsius) from advanced very high resolution radiometer from 18 January 1994. A segment of the trajectory of the drifter 696 between 3 and 29 January 1994 is superimposed. The circle indicates the initial position. 

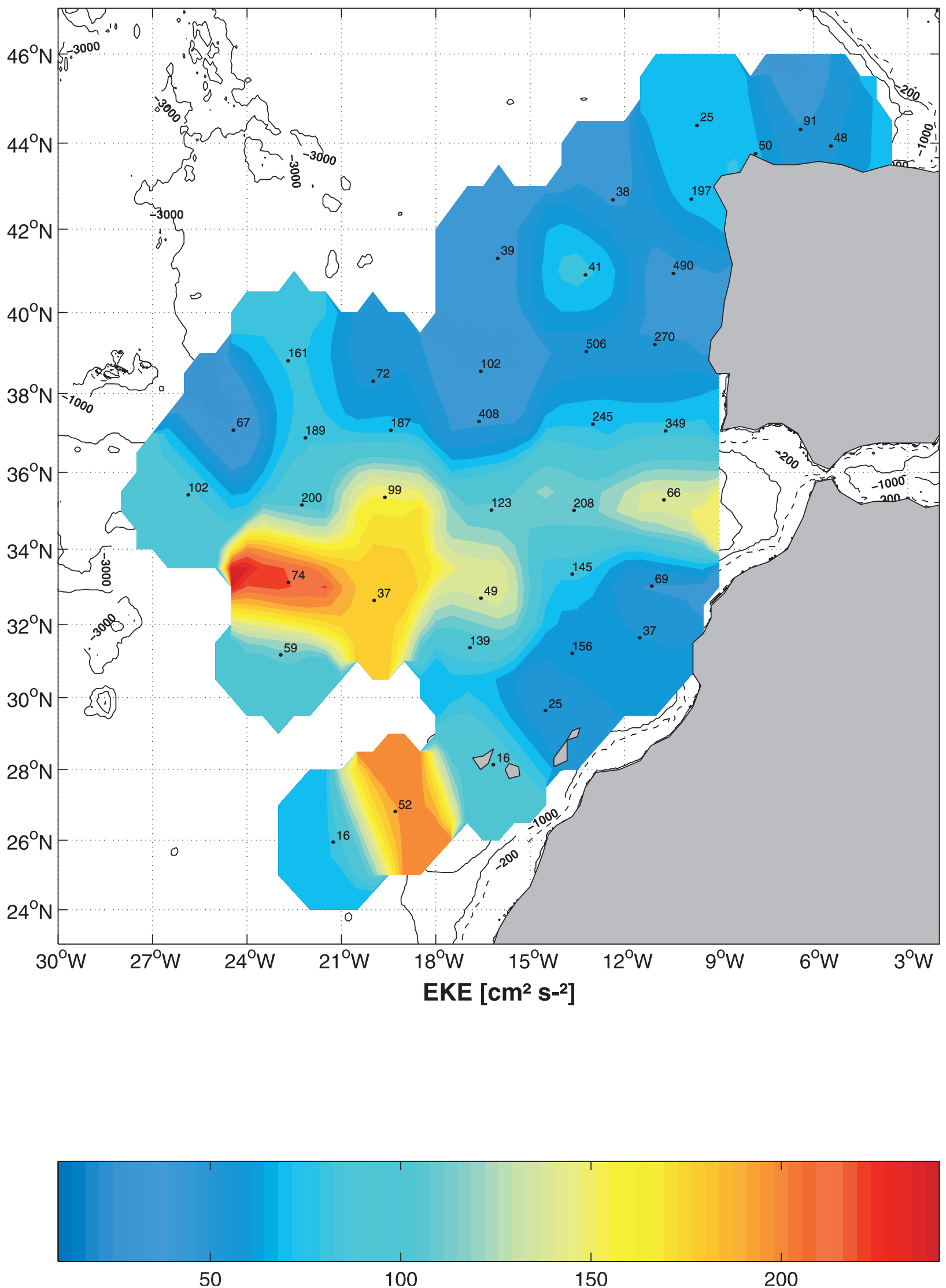

Figure 7. Spatial distribution of EKE $\left(\mathrm{cm}^{2} \mathrm{~s}^{-2}\right)$ from drifter data in boxes of $2^{\circ}$ latitude $\times 3^{\circ}$ longitude. The dots represent the average position of drifters in each box. The number of observations in these bins is indicated. 


\section{EKE $\left[\mathrm{cm}^{2} \mathrm{~s}^{-2}\right]$}
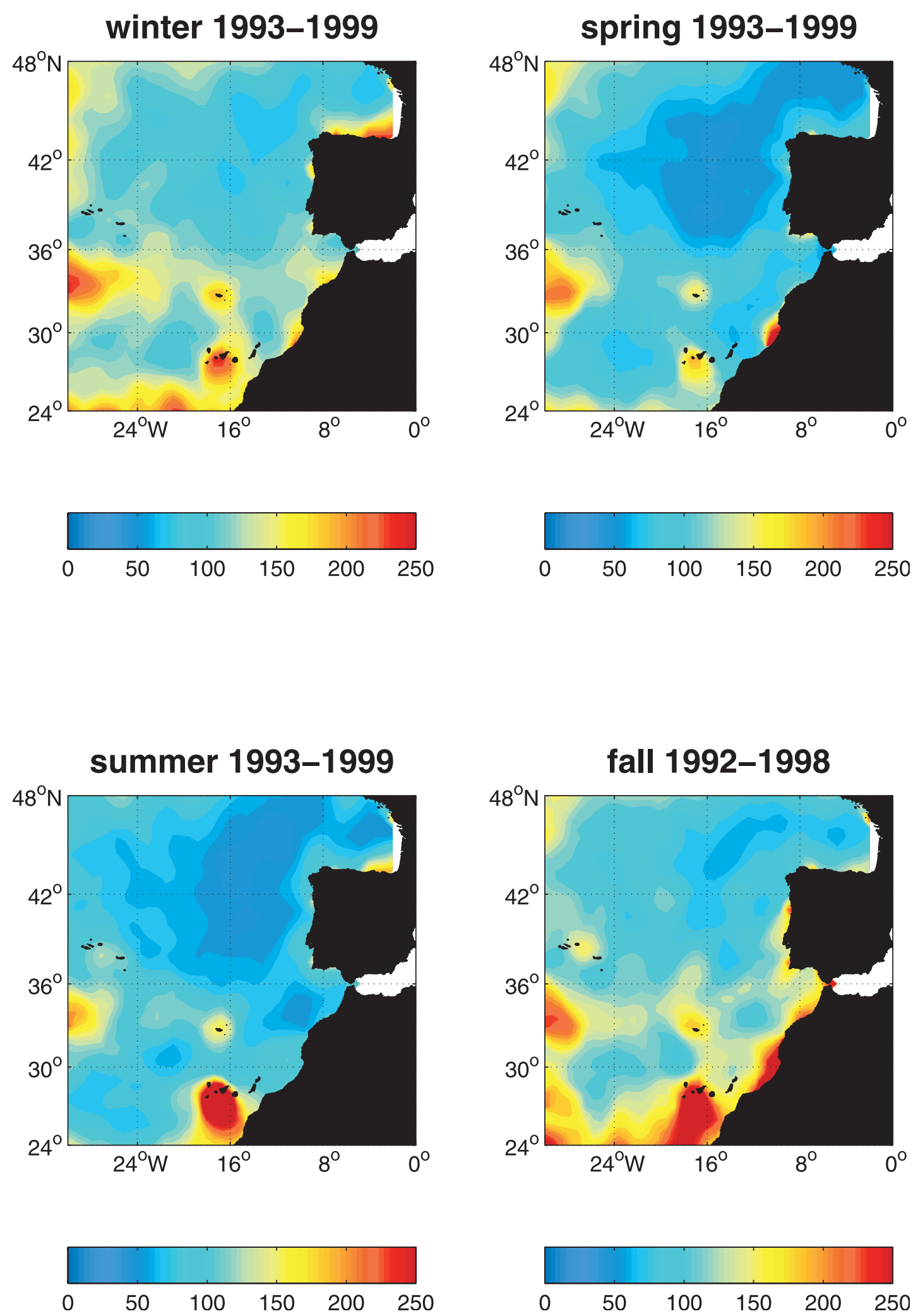

Figure 8a. Seasonal averages of $\operatorname{EKE}\left(\mathrm{cm}^{2} \mathrm{~s}^{-2}\right)$ in the northeast Atlantic obtained from altimetry (1992/1993-1999). 


\section{EKE $\left[\mathrm{cm}^{2} \mathrm{~s}^{-2}\right]$}

1993
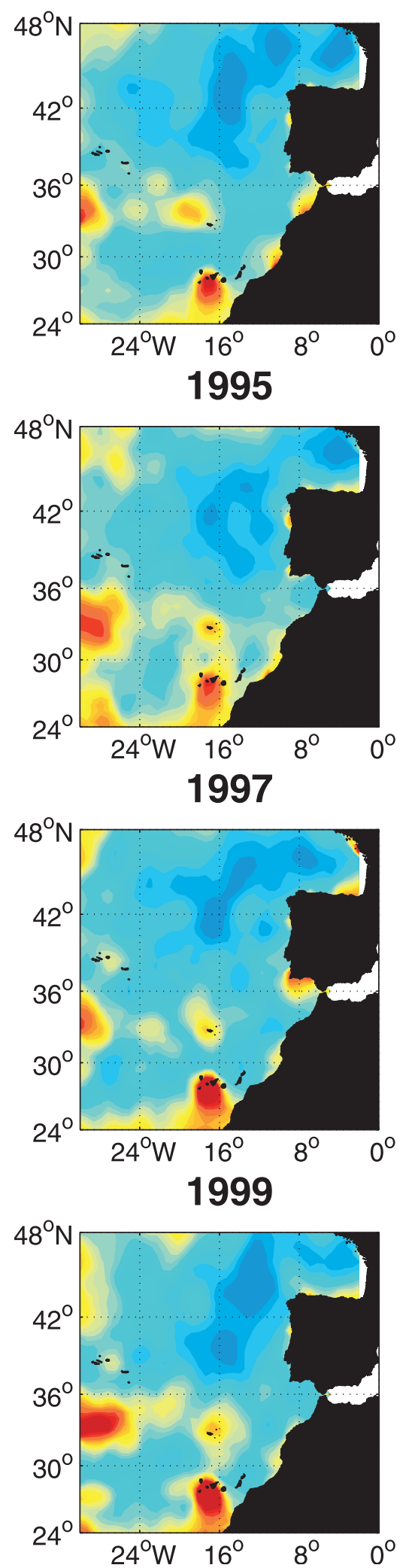

1994
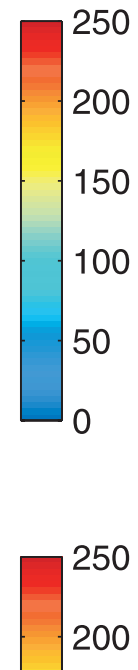

150

100

50
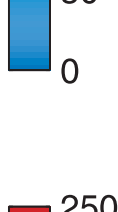

200

150

100

50

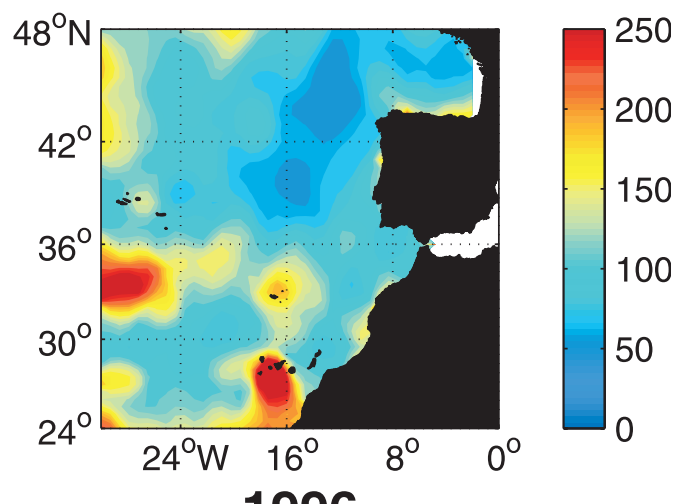

1996
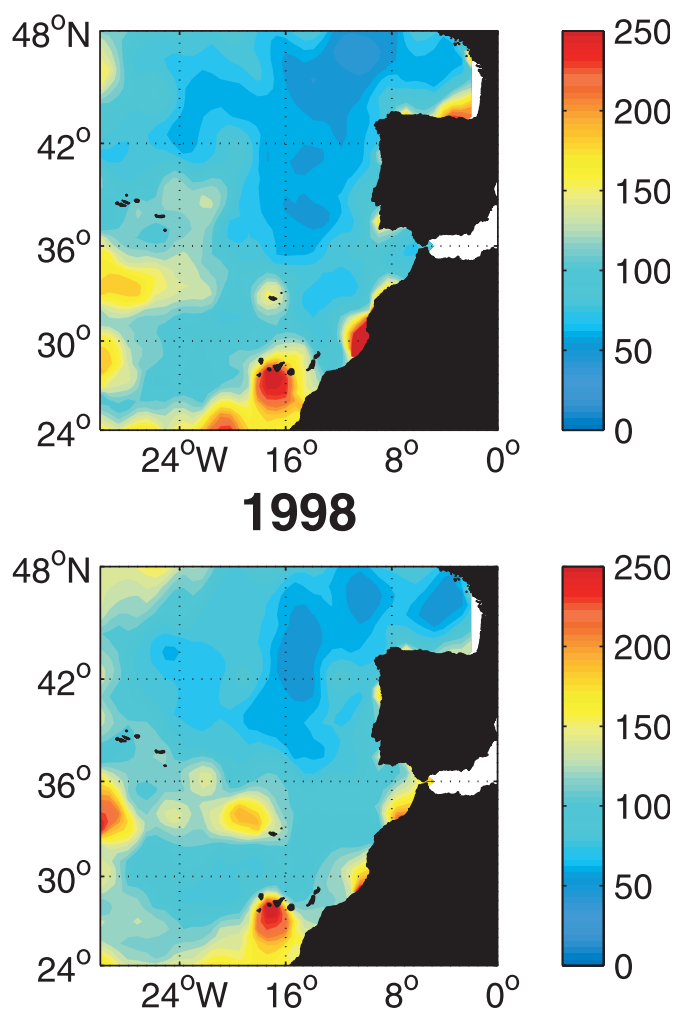

Figure 8b. Annual averages of EKE $\left(\mathrm{cm}^{2} \mathrm{~s}^{-2}\right)$ in the northeast Atlantic obtained from altimetry (1992/ 1993-1999). 

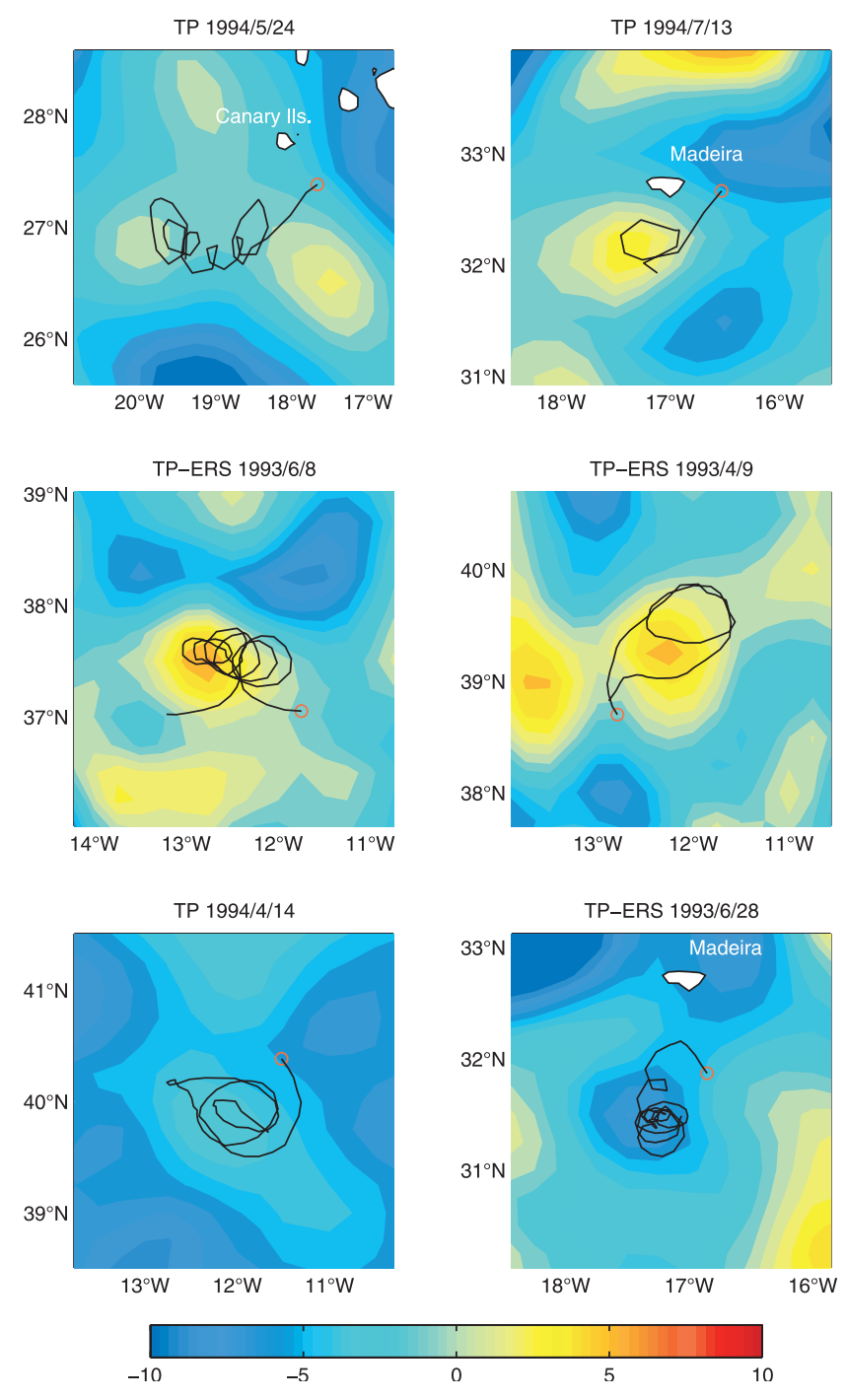

Figure 9. Eddies and meanders observed in the northeast Atlantic using drifter trajectories (black lines) and altimetry sea level anomaly data (centimeters) (colored shading) obtained from ERS and TOPEX/ Poseidon satellites. 